\title{
əobserved Link of Extreme Hourly Precipitation Changes to Urbanization over Coastal South China
}

\author{
MENGWEN WU \\ State Key Laboratory of Severe Weather, Chinese Academy of Meteorological Sciences, Beijing, and Institute of Meteorological \\ Sciences, Zhejiang Meteorological Bureau, Hangzhou, and University of Chinese Academy of Sciences, Beijing, China \\ YALI LUO \\ State Key Laboratory of Severe Weather, Chinese Academy of Meteorological Sciences, Beijing, and Collaborative \\ Innovation Center on Forecast and Evaluation of Meteorological Disasters, Nanjing University of Information \\ Science and Technology, Nanjing, China \\ FEI CHEN \\ State Key Laboratory of Severe Weather, Chinese Academy of Meteorological Sciences, Beijing, China, and \\ National Center for Atmospheric Research, Boulder, Colorado \\ WAI KIN WONG \\ Hong Kong Observatory, Hong Kong, China
}

(Manuscript received 22 October 2018, in final form 7 April 2019)

\begin{abstract}
Understanding changes in subdaily rainfall extremes is critical to urban planners for building more sustainable and resilient cities. In this study, the hourly precipitation data in 1971-2016 from 61 rain gauges are combined with historical land-use change data to investigate changes in extreme hourly precipitation (EXHP) in the Pearl River delta (PRD) region of South China. Also, 120 extreme rainfall events (EXREs) during 2011-16 are analyzed using observations collected at densely distributed automatic weather stations and radar network. Statistically significant increase of hourly precipitation intensity leads to higher annual amounts of both total and extreme precipitation over the PRD urban cluster in the rapid urbanization period (about 1994-2016) than during the preurbanization era (1971 to about 1993), suggesting a possible link between the enhanced rainfall and the rapid urbanization. Those urbanization-related positive trends are closely related to more frequent occurrence of abrupt rainfall events with short duration $(\leq 6 \mathrm{~h})$ than the continuous or growing rainfall events with longer duration. The 120 EXREs in 2011-16 are categorized into six types according to the originating location and movement of the extreme-rain-producing storms. Despite the wide range of synoptic backgrounds and seasons, rainfall intensification by the strong urban heat island (UHI) effect is a clear signal in all the six types, especially over the inland urban cluster with prominent UHIs. The UHI thermal perturbation probably plays an important role in the convective initiation and intensification of the locally developed extreme-rain-producing storms during the daytime.
\end{abstract}

\section{Introduction}

More than half of the global population now resides in urban areas (Grimm et al. 2008), and that number is

D Denotes content that is immediately available upon publication as open access.

Corresponding author: Dr. Yali Luo,ylluo@cma.gov.cn expected to increase to $60 \%$ by 2030 and $70 \%$ by 2050 (UN Department of Economic and Social Affairs, Population Division 2011). Urban areas, especially coastal cities, are vulnerable to heavy rainfall-induced flood exposure that is increasing in the changing climate

Publisher's Note: This article was revised on 14 August 2019 to correct the first author's affiliations, which were not correctly presented when originally published. 


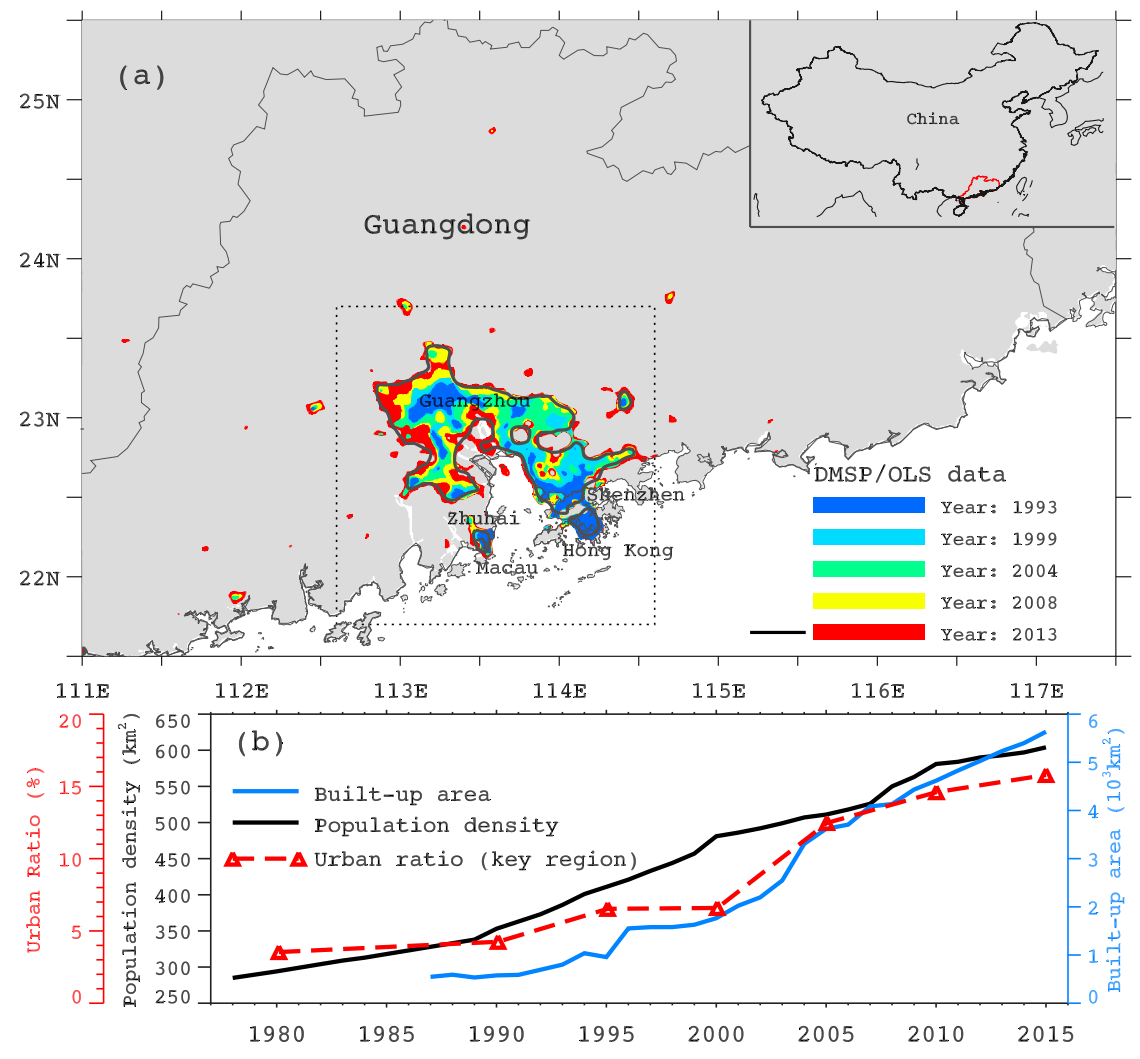

FIG. 1. (a) The urban region (color shading) in Guangdong province identified by the DMSP/OLS nighttime lights data in five different years. The bold black line represents the PRD urban region in 2013, which is also used in most of the following figures. The dashed rectangle denotes the key region defined in this study $\left(21.7^{\circ}-23.7^{\circ} \mathrm{N}, 112.6^{\circ}-114.6^{\circ} \mathrm{E}\right)$. The locations of the major cities in the PRD are labeled out. (b) Evolution of urbanization reflected by time series of the population density $\left(\mathrm{km}^{2}\right)$ and built-up area $\left(10^{3} \mathrm{~km}^{2}\right)$ in Guangdong and the urban ratio (\%) within the key region based on the land-use data.

(Hallegatte et al. 2013). The majority of previous studies suggested that daily extreme rainfall has increased in more regions than it has decreased in a warming world (Min et al. 2011; Seneviratne et al. 2012; Westra et al. 2013; Donat et al. 2016; Seneviratne et al. 2016). However, engineering practices and urban infrastructure design demand information about changes in subdaily (e.g., hourly or shorter) rainfall.

Subdaily precipitation extremes are often produced by convective events that are affected by complex interactions among mesoscale dynamics, cloud microphysical processes, and underlying surface forcing. Current understanding of the changes in subdaily extreme precipitation is very limited (Zhang et al. 2017) because of lack of high-resolution, long-term observations and limited knowledge about the physical mechanisms that govern the evolution of convective events. Climate models are not able to simulate such events well (Siler and Roe 2014; Z. H. Jiang et al. 2017; Pfahl et al. 2017), making it difficult to attribute past changes and to assess future changes in shortduration precipitation extremes. Moreover, factors affecting changes in short-duration precipitation extremes over urban environments are even less known because of complex and sometimes compensating effects of cities, namely, the destabilization caused by urban heat island (UHI)-induced thermal perturbation and its downstream rainfall enhancements translation (Huff and Vogel 1978; Hjelmfelt 1982; Bornstein and Lin 2000; Craig and Bornstein 2002; Niyogi et al. 2011), the buildingbarrier and thermal effects of urban canyons (Bornstein and Lin 2000; Guo et al. 2006; Zhang et al. 2009; Miao et al. 2011), and the anthropogenic aerosol emissions for cloud condensation nuclei (CCN) sources (Rosenfeld 2000; Bell et al. 2009; Jin and Shepherd 2008; Ntelekos et al. 2009).

Guangdong province, located in coastal South China (Fig. 1a), is exposed to high flood-induced risk (Hallegatte et al. 2013) because of the high frequency of heavy rainfall at hourly (Luo et al. 2016) to longer scales (Zheng et al. 2016). The heavy rainfall in South 

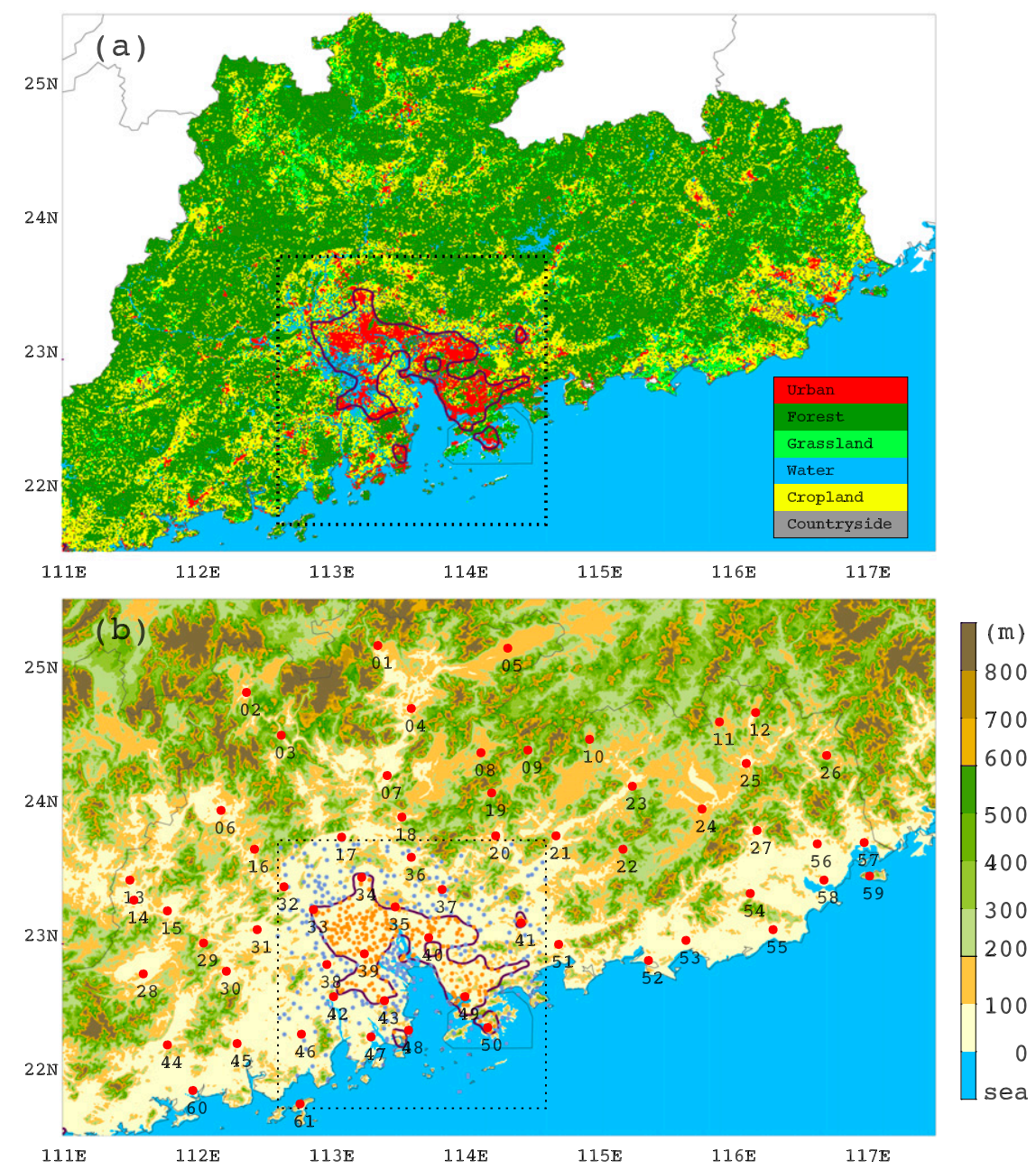

FIG. 2. (a) Land-use map over Guangdong in 2015, overlaid with the PRD urban region boundary based on the DMSP/OLS nighttime lights data in 2013 (solid black). (b) Spatial distributions of 61 national-level stations (red dots) in the analysis domain. Each station is assigned a number, which is also used in many of the following figures. The key region is outlined by dotted rectangle. Dots of smaller sizes represent AWSs within the key region, with orange/lavender ones denoting stations inside/outside of the PRD urban region. Shading represents the topography.

China is influenced by large-scale to synoptic-scale weather systems including the Asian summer monsoon (Ding 1994), subtropical ridge of high pressure in western North Pacific and heat low over southern and southwestern parts of China (Ramage 1952), cyclonic vortex anomalies moving from downstream of the Tibetan Plateau (Huang et al. 2018), and tropical cyclones ( $\mathrm{Li}$ and Zhou 2015), as well as mesoscale forcing associated with an underlying surface (such as land-sea contrast and coastal mountains) cold pool generated by significant convective storms (Wang et al. 2014; Wu and Luo 2016; Liu et al. 2018).

The rapid expansion of urban areas in Guangdong province during the past two decades (Fig. 1b) led to the formation of city clusters in the Pearl River delta (PRD) (Fig. 1a). In 2016, the PRD covered an area of about $42200 \mathrm{~km}^{2}$ with a population over 57 million, accounting for $52.0 \%$ of the total population in Guangdong (Guangdong Statistical Bureau 2016). It encompasses a cluster of big cities, including the capital city of Guangdong province (Guangzhou) at its northern apex, Hong Kong and the Special Economic Zone (SEZ) of Shenzhen at the southeast, while Macao and Zhuhai SEZ over the southwestern part of PRD. Based on satellite data in 1998-2009, Li et al. (2011) suggest that the urban areas in PRD experience more (less) occurrences of heavy (light) precipitation compared to surrounding suburban regions. Understanding changes in subdaily precipitation extremes 
TABLE 1. Classification of the hourly extreme precipitation in 1971-2016 according to the temporal evolution of hourly precipitation in the $3 \mathrm{~h}$ prior to the hourly extreme.

\begin{tabular}{lcc}
\hline $\begin{array}{c}\text { Temporal } \\
\text { evolution type }\end{array}$ & $\begin{array}{c}\text { Hourly rainfall rates in } 3 \mathrm{~h} \text { prior to the extreme rainfall hour }\left(R_{-1}, R_{-2},\right. \\
R_{-3}, \text { respectively) compared with the extreme hourly rainfall }\left(R_{0}\right)\end{array}$ & $\begin{array}{c}\text { Contribution to total occurrence of the } \\
\text { non-TC hourly precipitation extremes (\%) }\end{array}$ \\
\hline Abrupt type & $\begin{array}{l}R_{-1}<0.1 R_{0} \text { and } R_{-2}<0.1 R_{0} \text { and } R_{-3}<0.1 R_{0} \\
\text { Growing type }\end{array}$ & 43.3 \\
& $\left(R_{-1}>R_{-2}\right.$ or $R_{-1}>R_{-3}$ or $\left.R_{-2}>R_{-3}\right)$ and at least one of \\
Continuous type & $\left(R_{-1}, R_{-2}, R_{-3}\right)>10 \%$ but $<R_{0}$ & 40.7 \\
At least one of $\left(R_{-1}, R_{-2}, R_{-3}\right)>R_{0}$ & 16.0 \\
\hline
\end{tabular}

and their relationship with urbanization is critical to urban policy makers for developing more sustainable and resilient cities in this region.

This study aims to investigate changes of extreme hourly precipitation in coastal South China with a focus on its possible relationship with the urbanization in PRD. To achieve this objective, the long-term changes in extreme hourly precipitation (EXHP; defined by the 95 th percentile) are analyzed using hourly precipitation observations at 61 national-level surface stations from 1971 to 2016. Then a total of 120 extreme rainfall events (EXREs) (with at least one record of hourly rainfall at $60 \mathrm{~mm}$ or more in the PRD region) during 2011-16 are further examined using observations collected by densely distributed automatic weather stations (AWSs) and radar network. The paper is organized as follows: The next section describes the data and analysis methods. Section 3 presents the changes of hourly precipitation extremes during 1971-2016. Section 4 classifies the EXREs from 2011 to 2016 into six types according to the characteristics in the movement of rainstorms, and compares between the strong- and weak-UHI subgroups for each type. A summary and conclusions are provided in section 5 .

\section{Data and analysis methods}

\section{a. Estimating the PRD urbanization}

This study combines historical land-use data, satellite-based nighttime lights dataset, and statistical data of population density and built-up area from the Guangdong Statistical Bureau (2016; http:// www.gdstats.gov.cn/) to assess the urbanization in PRD. The historical land-use data of horizontal resolution at $1 \mathrm{~km}$ are available from the Resources and Environment Scientific Data Center, Chinese Academy of Sciences (http://www.resdc.cn/data.aspx? DATAID =98) for 1980, 1990, 1995, 2000, 2005, and 2015 based on visual interpretation and digitalization of the 30-m Landsat TM/ETM satellite images (Gong et al. 2013). They include six land-use types: croplands, forest, grasslands, water bodies, built-up lands, and others. Because of its high accuracy in monitoring land-use change in China, this dataset has been extensively used in the fields of land resource surveys, hydrology, and ecology (e.g., Li et al. 2015; Liu et al. 2014). Moreover, the fourth version composite satellitebased nighttime lights data gathered during 1992-2013 derived from the Defense Meteorological Satellite Program's Operational Linescan System (DMSP/OLS) of the United States (https://ngdc.noaa.gov/eog/dmsp/ downloadV4composites.html) are utilized. The digital numbers (DN) values of 50,56 , and 57 are used as the urban thresholds for the years of 1992, 1995, and in and after 2000, respectively, based on Wang et al. (2013).

The aforementioned three independent data sources all reveal a rapid urbanization in the PRD region since the early to mid-1990s, as suggested by the continuous increases of the built-up area, population density, and ratio of urban land use, as well as the expansion of nighttime light (Figs. 1a,b). The boundary of the PRD urban region is represented hereafter by the contour line derived from the DMSP/OLS data in 2013 (Fig. 1a), which agrees well with the land-use data in 2015 (Fig. 2a).

\section{b. Analysis of the long-term changes in hourly precipitation extremes}

This study utilizes the long-term, gauge-based hourly precipitation dataset provided by the National Meteorological Information Center (NMIC) of the China Meteorological Administration (CMA; http:// data.cma.cn/data/online.html?t=1) to analyze the

TABLE 2. Number of the categorized 2011-16 extreme rainfall events.

\begin{tabular}{lccr}
\hline \multicolumn{1}{c}{ Type } & Strong-UHI events & Weak-UHI events & Total \\
\hline Local/SW wind & 18 & 20 & 38 \\
Local/shear line & 17 & 8 & 25 \\
Migratory-NW & 20 & 14 & 34 \\
Migratory-SW & 3 & 10 & 13 \\
Migratory-NE & 6 & 0 & 6 \\
Migratory-S & 4 & 0 & 4 \\
Total & 68 & 52 & 120 \\
\hline
\end{tabular}



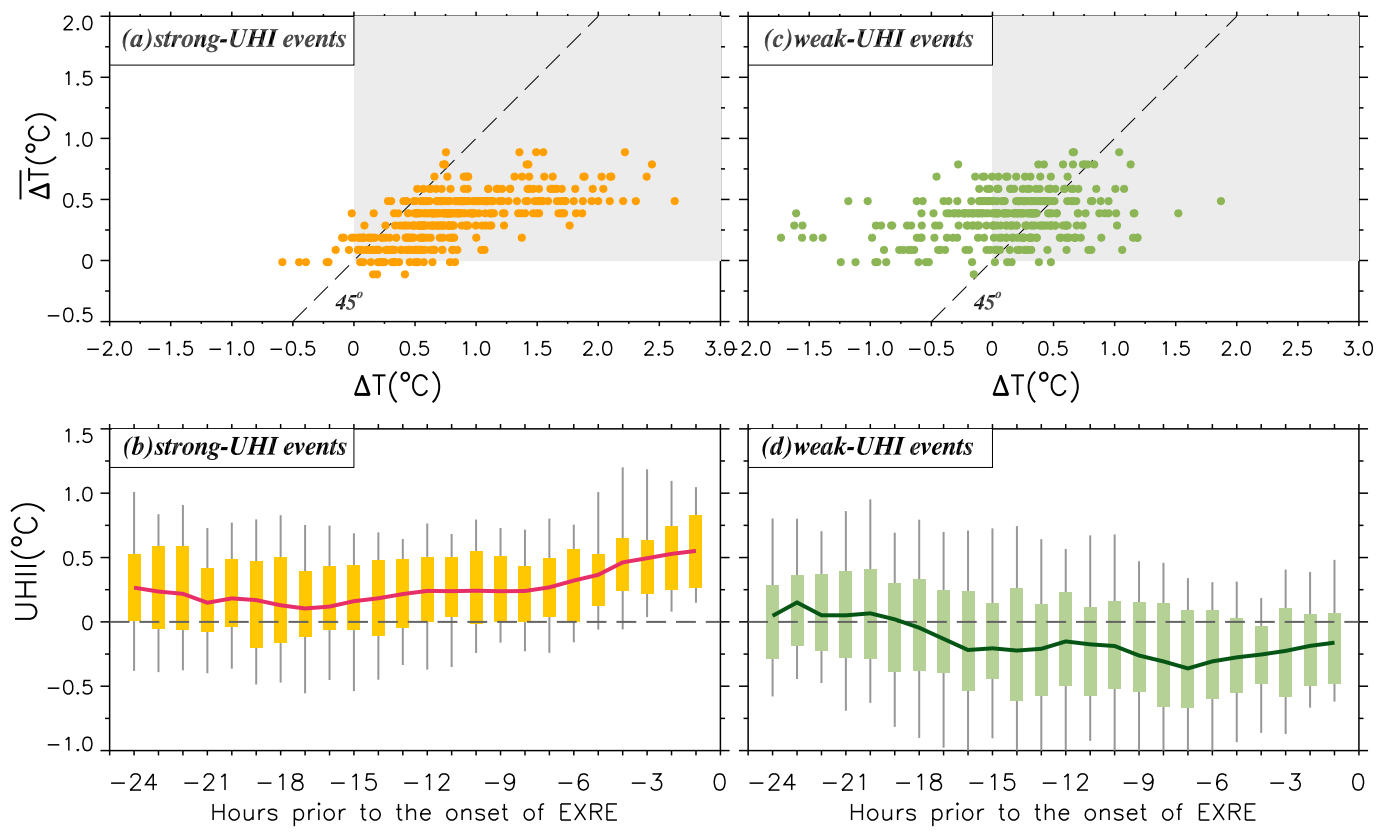

FIG. 3. (a),(c) Scatterplot of $\Delta T$ and its corresponding $\overline{\Delta T}$ at each of the $6 \mathrm{~h}$ prior to the onset of the 2011-16 EXREs with (a) a strong-UHI and (c) a weak-UHI, respectively. (b),(d) Box-and-whisker plots of UHII for the 2011-16 EXREs with (b) a strong-UHI and (d) a weak-UHI, respectively, showing the interquartile range (rectangle), outliers (i.e., the 10th and 90th percentile as whiskers), and mean (solid line).

long-term changes of hourly extreme precipitation over the analysis domain (Fig. 2b). A strict qualitycontrol procedure has been applied to the dataset by NMIC consisting of a climatological limit value test, a station extreme value test, an internal consistency test, and a comparison with manually checked daily rainfall data. This dataset has been extensively used to investigate the characteristics of subdaily precipitation over China (e.g., Yu et al. 2007; Li et al. 2008; Yuan et al. 2012; Luo et al. 2016; Guo et al. 2017). This study utilizes 60 stations in Guangdong and one station in Hong Kong that have continuous records from 1971 to 2016 (distribution shown in Fig. 2b). Each of the 61 stations has over $95 \%$ of valid hourly data each year.

The EXHP at each station is defined using the 95th percentile of the distribution function during 1971-2016 as the threshold. The threshold values increase southward from about 6 to $13 \mathrm{~mm} \mathrm{~h}^{-1}$ (not shown). The rainfall amount and occurrence frequency of the EXHP are calculated as the annual rainfall amount and the total number of hours of the EXHP, respectively. The EXHP intensity is calculated as the rainfall amount divided by its occurrence frequency. The rainfall amount, occurrence frequency, and intensity of hourly precipitation $\left(\geq 0.1 \mathrm{~mm} \mathrm{~h}^{-1}\right)$ are defined similarly. Their long-term trends are estimated using a linear tendency method. The significances of the trends are examined utilizing the Mann-Kendall nonparametric test
(Mann 1945; Kendall 1975). The test has been applied extensively including in studies that test for changes in rainfall extremes (Alexander and Arblaster 2009; Westra et al. 2013). To make the trends more comparable among the various variables (i.e., precipitation amount, occurrence frequency, and intensity), relative percentage changes are calculated using the equation below:

$$
\Delta=\frac{10 \times S}{P}(100 \%),
$$

where $\Delta$ is the relative change in precipitation $\left(\%\right.$ decade $\left.^{-1}\right), S$ is the slope of the linear model, and $P$ is the precipitation value in the start year estimated using the linear regression equation. The significances of the linear regression equation are examined using the $F$ test (Lomax and Hahs-Vaughn 2007).

Moreover, rainfall produced by tropical cyclones (TCs) is identified with an objective synoptic analysis technique (OSAT; Ren et al. 2006, 2007, 2011). This method uses the distance from TC center and the closeness and continuity between neighboring raining stations to trace TC-influenced rain belts. An extreme hourly precipitation record in this study is classified as a TC-induced EXHR record if it occurs within the identified TC-influenced rain belts; otherwise it is a non-TC record. Previous studies have suggested that rainfall trends over China are complicated by TCs 
(a) Composite $\Delta \theta$ of Strong UHI events

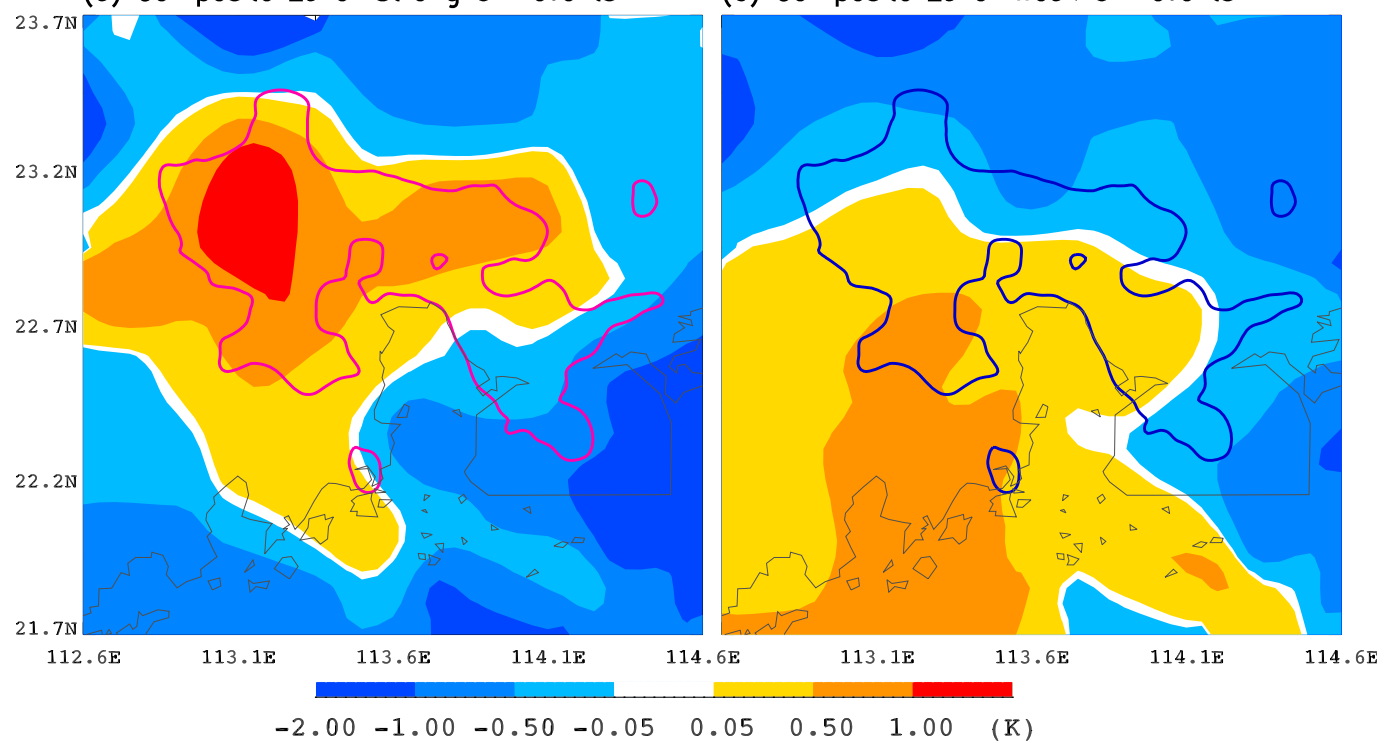

FIG. 4. The pre-event potential temperature perturbation $(\Delta \theta)$ for the 2011-16 EXREs with (a) a strong-UHI and (b) a weak-UHI, respectively. The hourly observations in the 3-h period prior to each EXRE onset are used in the calculation.
(Chang et al. 2012; Li et al. 2017), and the TC-induced hourly precipitation extremes contribute about $20 \%$ to the total occurrence frequency of the extremes over coastal South China (Luo et al. 2016). The precipitation excluding the TC-produced is termed as non-TC precipitation hereafter. Furthermore, the hourly extreme precipitation records are classified into the abrupt, growing, and continuous types according to the temporal evolution features of the hourly rainfall series (Table 1; Liang and Ding 2017), and into the short(1-6h), moderate- (7-12 h), and long-duration ( $>12 \mathrm{~h})$ types based on the time span of continuous rainfall ( $>0.1 \mathrm{~mm} \mathrm{~h}^{-1}$ with at most 1 -h intermittence).

\section{c. Analysis of the 2011-16 extreme rainfall events}

To complement the 46-yr linear tendency analysis, the possible relationship between a strong UHI effect and the 2011-16 EXREs are examined. Both the quality-controlled hourly records at densely distributed AWSs and 10-min mosaic radar reflectivity in Guangdong are used to provide detailed information about the convective events. The EXRE is defined as a rain system that produces at least one rainfall record of $>60 \mathrm{~mm} \mathrm{~h}^{-1}$ observed by the AWSs within the key region (defined as a $2^{\circ} \times 2^{\circ}$ region in the analysis domain; dotted rectangle in Fig. 2) covering the entire PRD urban cluster and the adjacent forest, cropland, and water. The 10-min radar images are adopted to verify the reliability of the extreme rainfall records, as well as to characterize the life cycle of the extreme-rain-producing convective systems. A total of 133 EXREs are found. Among them 13 cases are featured by an extensive cyclonic vortex at $850 \mathrm{hPa}$ over South China that helps produce a persistent (duration $>1$ day), extensive precipitation region ( $>1000 \mathrm{~km}$ on the radar image). The large-scale forcing, rather than the UHI-influenced local environment, is believed to play a dominant role in modulating the 13 EXHRs. Contrastingly the other 120 EXREs are mainly produced by MCSs lasting less than $24 \mathrm{~h}$. As the focus of this study is the possible link between the UHI and EXHP, the 13 EXREs with such large-scale vortices are excluded from the following analysis.

For the remaining 120 EXREs, the intensity of the PRD UHI during the onset of each EXRE (UHII) is calculated using the equations below:

$$
\begin{aligned}
\mathrm{UHII} & =\Delta T-\overline{\Delta T}, \\
\Delta T & =T_{u}-T_{r}, \quad \text { and } \\
& \sum_{\overline{\Delta T}}^{2016} \sum_{\text {day }+5}^{2011} \Delta T \\
6 \times 11 &
\end{aligned}
$$

where $T_{u}$ and $T_{r}$, respectively, are the hourly surface air temperatures averaged over the densely distributed AWSs within the PRD urban region (small orange dots in Fig. 2b) and outside the PRD urban region (small 

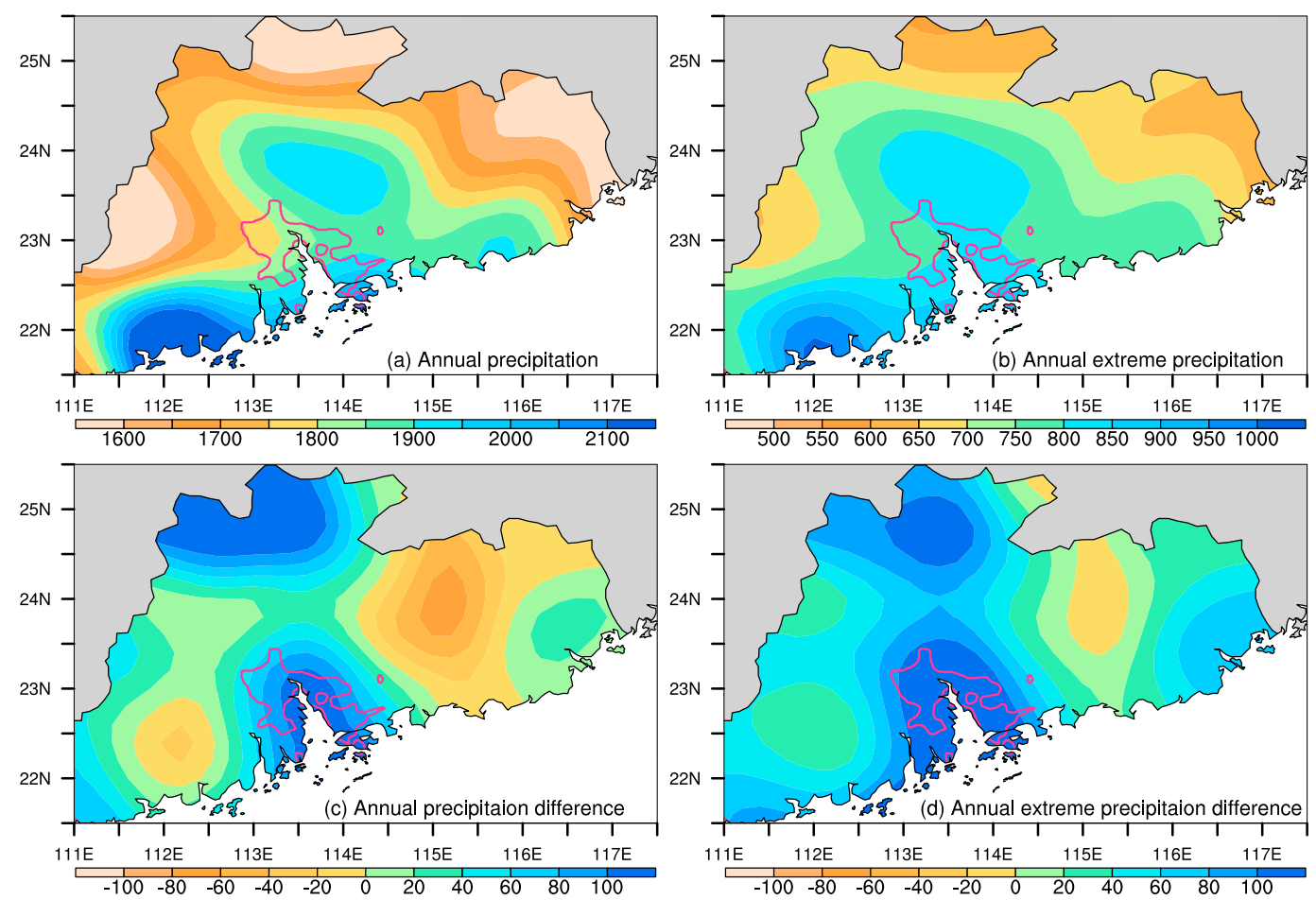

FIG. 5. (a) Annual precipitation amount $\left(\mathrm{mm} \mathrm{yr}^{-1}\right)$ averaged during 1971-2016 and (c) its difference between 1994-2016 and 1971-93. (b),(d) As in (a),(c), respectively, but for the extreme hourly precipitation ( $>95$ th percentile).

purple dots in Fig. 2b); thus $\Delta T$ roughly represents the hourly temperature difference between the PRD urban cluster and its surrounding areas. To remove the seasonal and diurnal variations of $\Delta T$, UHII is represented by the difference between $\Delta T$ and $\overline{\Delta T}$. The value of $\overline{\Delta T}$ is calculated by averaging $\Delta T$ at the same local solar time (LST) during 11 days (from -5 to +5 days) in 2011-16. For example, if the $\Delta T$ value is calculated at 1500 LST 12 June 2013, its corresponding $\overline{\Delta T}$ is the average of $66 \Delta T$ values at 1500 LST from 7 to 17 June in 2011-16. Thus, UHII $>0$ means that the UHI intensity prior to each EXRE onset is stronger than its corresponding multiyear average intensity. The pre-event hourly $\operatorname{UHII}_{i}(i=1,2, \ldots, 24$; denoting the hour prior to the EXRE onset) values are calculated for each EXRE. Existence of a strong PRD UHI for an EXRE is defined as at least four out of six hours with $\mathrm{UHII}_{i}>0$ ( $i=1-6)$; these EXREs are referred to as the strongUHI events. The rest EXREs have at most three out of six hours with $\mathrm{UHII}_{i}>0(i=1-6)$ and are classified into the weak-UHI events. Existence (lack) of such a strong UHI is found for 68 (52) EXREs (Table 2). Composites of the UHII for the strong- and weakUHI events are shown in Fig. 3. The mostly (99.25\%) positive values of the multiyear average $\overline{\Delta T}$ indicate the presence of the PRD UHI with varying intensities from nearly zero to about $1^{\circ} \mathrm{C}$ (Figs. 3a,c), probably in association with the seasonal and diurnal variations of UHI intensity (Landsberg 1981; Shepherd 2005; Ren and Zhou 2014). The hourly UHII values are mostly positive in the 4-h preonset periods and increases rapidly 6 -h before the onset of the strong-UHI events (Figs. 3c,d). For the weakUHI events, about $68.7 \%$ of the $\Delta T$ has positive values, reflecting presence of an UHI prior to the events' onset. A certain fraction $(31.3 \%)$ of negative $\Delta T$ can be contributed by rain evaporative cooling due to previous convection in the urban cluster that might occur occasionally prior to the EXREs. Mostly negative values of UHII are observed in the 6-h preonset periods (Fig. 3d), suggesting UHI intensities $(\overline{\Delta T})$ are weaker than the multiyear average.

To examine the spatial distribution of UHI, the surface potential temperature perturbation $(\Delta \theta)$ at each station is calculated as the deviation from the spatialaverage value of $\theta$ within the key region at each hour. This method largely removes the seasonal and diurnal variations of surface potential temperature $(\theta)$. The distribution of $\Delta \theta$ averaged during 1-3 h prior to each EXRE is compared between the strong- and weakUHI EXREs (Fig. 4). A prominent surface warm center over the inland PRD urban region is noticed in the average $\Delta \theta$ field of the strong-UHI events (Fig. 4a). Such a prominent warm center does not exist in the 
weak-UHI events, as smaller positive $\Delta \theta$ values are widely distributed in the southwest part of the key region (Fig. 4b).

The 2011-16 EXREs are then categorized into six types mainly based on the rain storms' initiation location and movement observed by the radar network. Specifically, the EXREs with extreme-rain-producing storms initiating and developing within the key region are selected first, and classified as either local/southwest (SW) wind type or local/shear line type according to their synoptic patterns on $925 \mathrm{hPa}$ using the ERAInterim reanalysis (Dee et al. 2011). The former has prevailing southwesterly airflows and the latter has a shear line over the key region. Then, all the other EXREs with extreme-rain-producing storms moving from outside the key region are classified into four types based on the direction the storms move into the key region, namely, the migratory-northwest (NW), migratory-northeast (NE), migratory-south (S), and migratory-southwest (SW) types.

To examine possible UHI impacts, rainfall distributions of the strong- and weak-UHI EXREs in the same type are compared. For this purpose, the normalized rainfall (NR) is calculated for each AWS in the key region following Eqs. (5)-(7):

$$
\begin{aligned}
R_{j} & =\sum_{1}^{n} R_{j k}(j=1, m ; k=1, n), \\
\bar{R} & =\frac{\sum_{1}^{m} R_{j}}{m}, \quad \text { and } \\
\mathrm{NR}_{j} & =\frac{R_{j}-\bar{R}}{\bar{R}},
\end{aligned}
$$

where $R_{j k}$ is event-accumulated rainfall amount of EXRE $k(k=1, n$; where $n$ is the total number of EXREs in a subgroup) at site $j(j=1, m$; where $m$ is the total number of AWSs in the key region), $R_{j}$ is rainfall accumulation of an EXRE subgroup at site $j, \bar{R}$ is the subgroup rainfall accumulation averaged over all the AWSs in the key region, and $\mathrm{NR}_{j}$ is the normalized rainfall anomaly at site $j$ relative to the domain average of the EXRE subgroup. This method is able to highlight local features of the rainfall distribution ( $Y u$ 2007; Dou et al. 2015).

\section{Changes in hourly precipitation extremes during 1971-2016}

Figures $5 \mathrm{a}$ and $5 \mathrm{~b}$ shows the spatial distributions of total precipitation amount and extreme precipitation

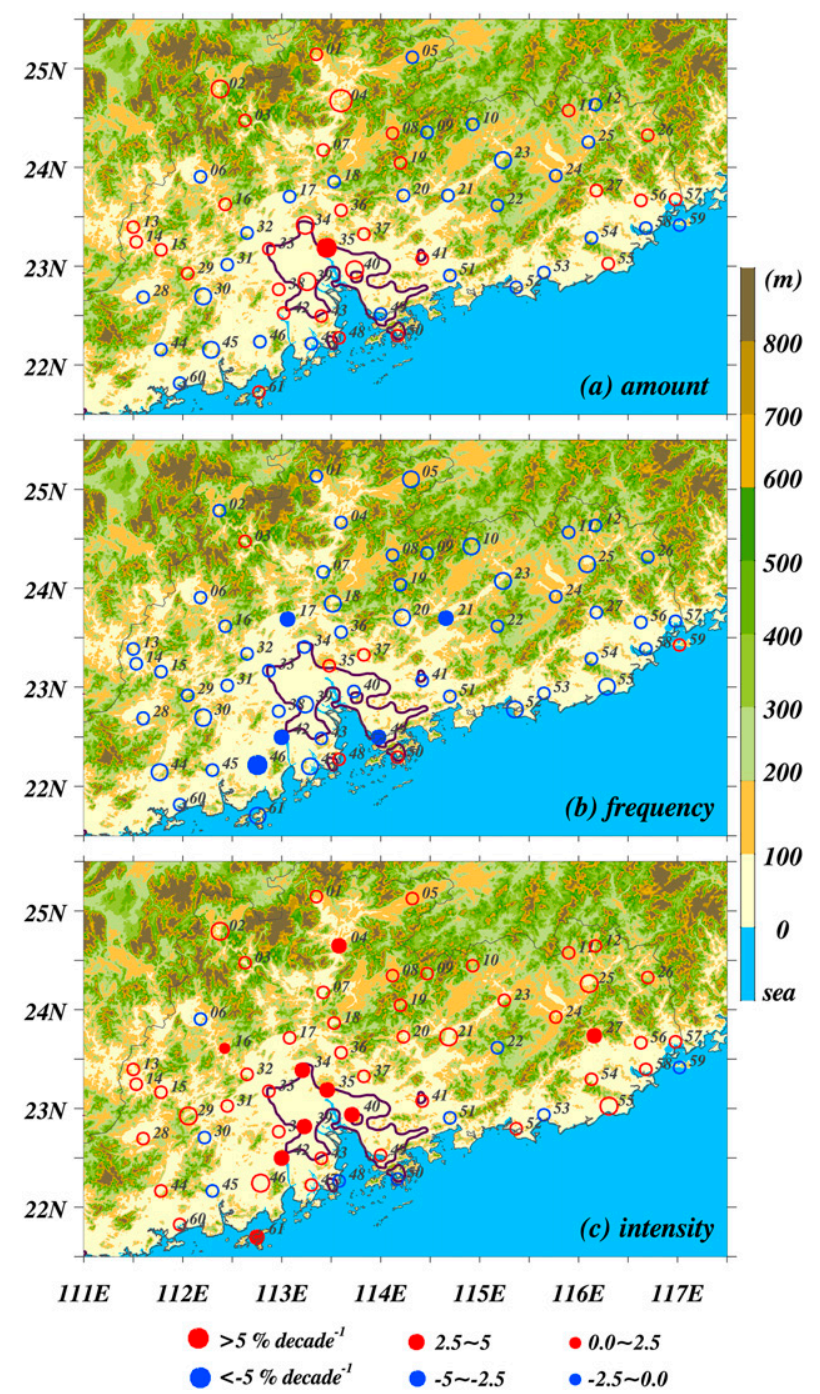

FIG. 6. The observed 1971-2016 changes $\left(\%\right.$ decade $\left.^{-1}\right)$ in the hourly precipitation $\left(\geq 0.1 \mathrm{~mm} \mathrm{~h}^{-1}\right)$ : (a) amount, (b) occurrence frequency, and (c) intensity. Dots (circles) denote significant (insignificant) trends at the 95\% confidence level using the Mann-Kendall test. Size of the dots and circles represents the various magnitudes of the changes. Shadings represent the topography.

amount over the analysis domain averaged during 1971-2016. The total precipitation amount has three peaks in the southwest coastal, central, and southeast coastal Guangdong, respectively, with the annual maximal precipitation amounts exceeding $2100 \mathrm{~mm} \mathrm{yr}^{-1}$ in the southwest center and of about $1900-50 \mathrm{~mm} \mathrm{yr}^{-1}$ in the other two centers. The inland PRD urban region, with an annual precipitation amount of about $1800 \mathrm{~mm} \mathrm{yr}^{-1}$, is located between the southwest and central precipitation centers. Such a distribution shows a largely similar pattern to that of the hourly extremes, except that the southwest and central 

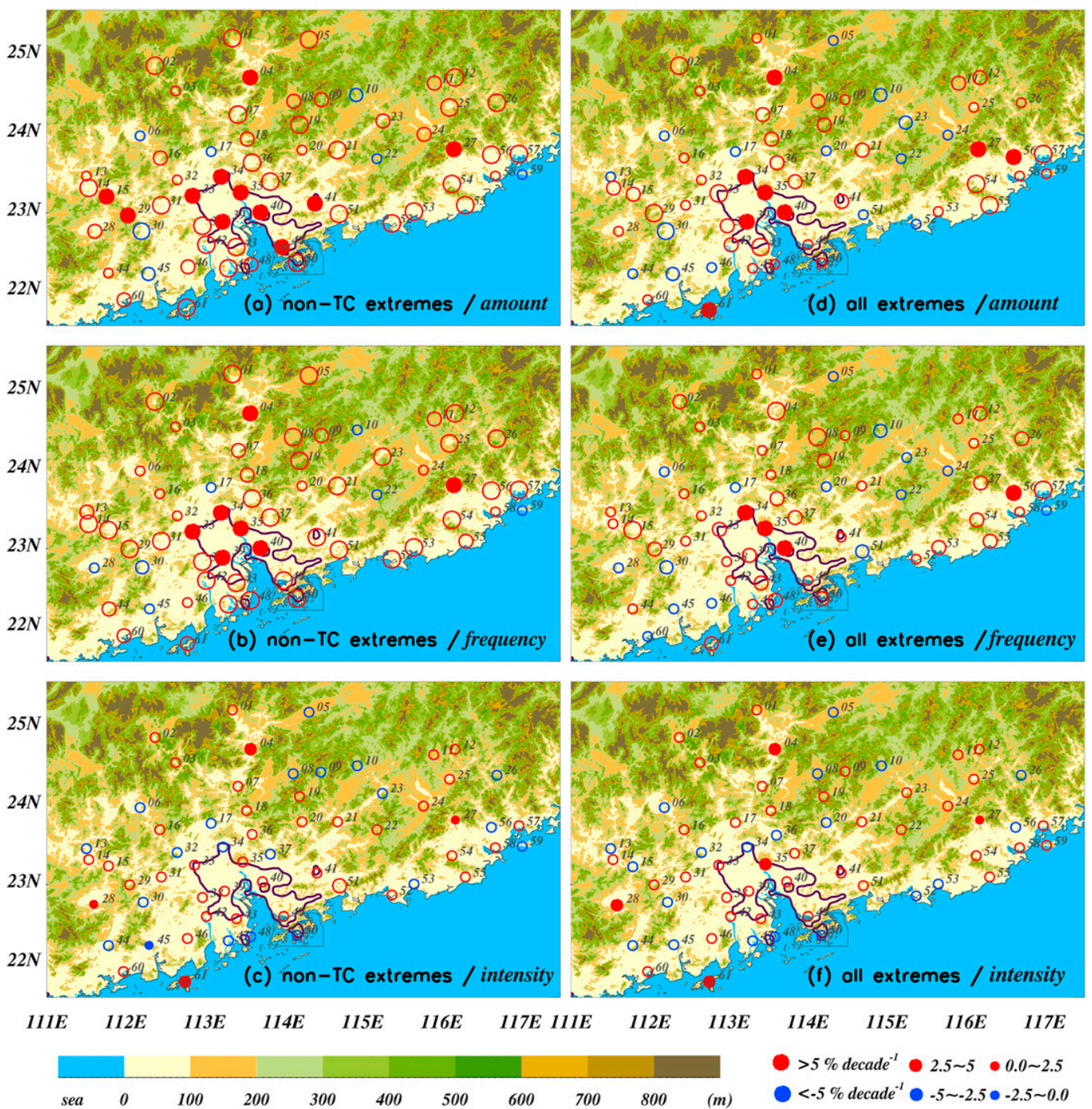

FIG. 7. (a)-(c) The observed 1971-2016 changes (\% decade $\left.{ }^{-1}\right)$ in the non-TC extreme hourly precipitation: (a) amount, (b) occurrence frequency, and (c) intensity. (d)-(f) As in (a)-(c), but for all the extreme precipitation including the TC-induced records. Dots (circles) denote significant (insignificant) trends at the $95 \%$ confidence level using the Mann-Kendall test. Size of the dots and circles denotes different magnitudes of the changes. Shadings represent the topography.

centers tend to connect crossing the east PRD urban region while the southeast center is less evident. Of interest is that the difference in the annual precipitation amount between the two 23-yr periods, that is, 1994-2016 minus 1971-93, reveals a prominent increase over the PRD region and the northern Guangdong region (Figs. 5c,d).

Figure 6 shows an increasing trend in the precipitation amount for most stations over the PRD region. Nevertheless, only the Guangzhou station (number 35) passes the significant test at $95 \%$ confidence level. Positive and negative trends are scattered outside the PRD region, but they are statistically insignificant. Negative trends in the occurrence frequency of hourly precipitation are observed at most stations over Guangdong, with only a few passing the significant test. By contrast, the hourly precipitation intensity exhibits an increasing trend at most stations. Importantly, the most significant increasing trends in the hourly precipitation intensity are mainly confined in the PRD region. These results suggest that more intense hourly precipitation, which is statistically significant over the PRD urban region (Fig. 6c), leads to the higher annual amounts of both total precipitation and extreme precipitation over the PRD in 1994-2016 than 1971-93 (Figs. 5c,d), suggesting a possible link to the rapid urbanization since mid-1990s. 

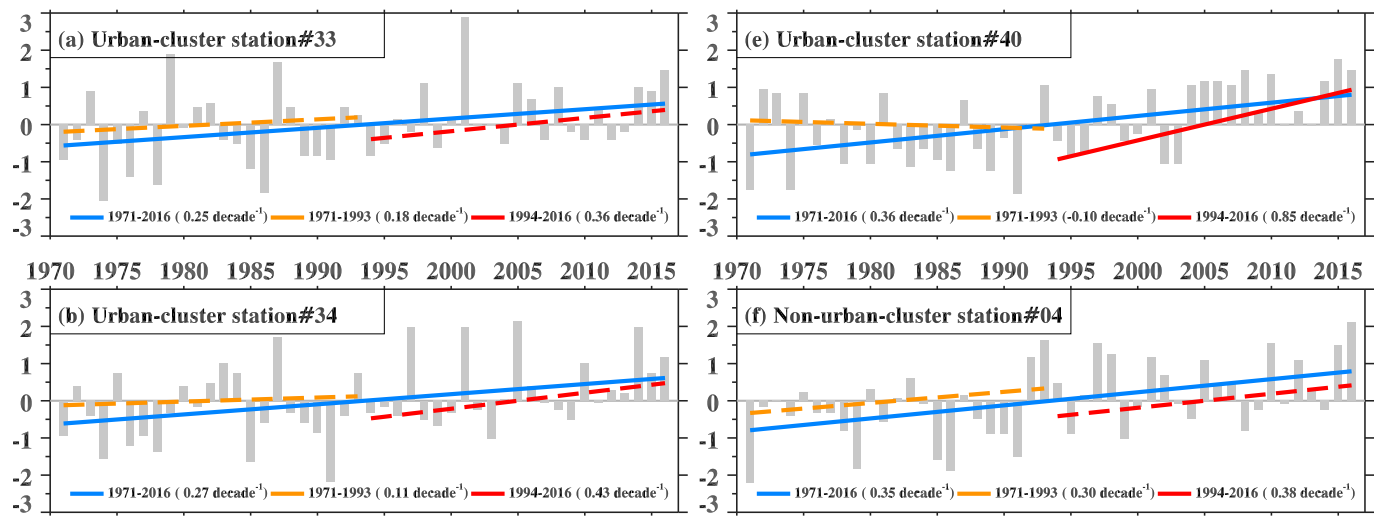

$\begin{array}{llllllllll}1970 & 1975 & 1980 & 1985 & 1990 & 1995 & 2000 & 2005 & 2010 & 2015\end{array}$
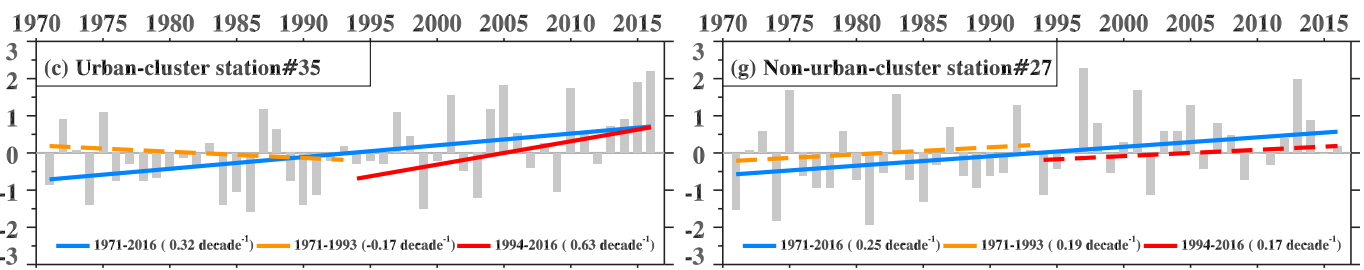

$\begin{array}{llllllllll}1970 & 1975 & 1980 & 1985 & 1990 & 1995 & 2000 & 2005 & 2010 & 2015\end{array}$ 1970197519801985199019952000200520102015

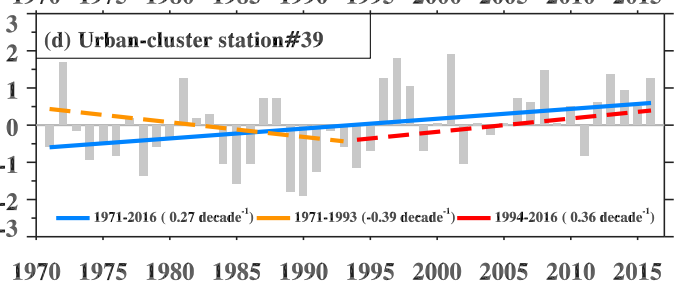

FIG. 8. (a)-(g) Time series (gray bars) and linear trends (solid lines) of the non-TC extreme hourly rainfall occurrence frequency at seven stations, with the station number labeled at the upper-left corner. The locations of the seven stations could be seen in Fig. 1a. The annual occurrence frequency is normalized by subtracting the mean value of the study period from the annual value of each year, and then divided by the corresponding standard deviation. Blue lines denote the linear trends for the period of 1971-2016, while the orange/red lines are for 1971-93/1994-2016. The solid (dashed) line denotes that the linear regression equation is significant (insignificant) at the $95 \%$ confidence level using the $F$ test. The corresponding slope values of the linear model for the three periods are shown in the bottom sequentially.

Changes in the amount, frequency, and intensity of the non-TC extreme hourly precipitation during 19712016 are shown in Figs. 7a-c. Data from 11 stations reveal statistically significant $(95 \%$ level) positive trends in the extreme rainfall amount, with six stations located in the PRD urban region while the other five stations scattered in the western, northern and eastern parts of Guangdong, respectively. The significant positive trends of the extreme rainfall frequency are observed only at seven stations over the analysis domain, mostly (five out of seven) in the PRD urban region, especially its inland portion. The extreme hourly precipitation intensity also increases at most of the PRD urban stations. However, the trends are insignificant at $95 \%$ level. These results suggest that the increased amount of non-TC precipitation extremes may mainly be caused by their more frequent occurrence over the PRD urban region. The inclusion of TC-induced extreme hourly rainfall results in a smaller number of stations with statistically significant positive trends of the amount ( 8 vs 11) (Fig. 7d vs Fig. 7a) and frequency (4 vs 7) (Fig. 7e vs Fig. 7b), which is qualitatively consistent with the finding of a reduction in landfalling TC occurrence over South China during 1975-2014 by Li et al. (2017). Note that the significant positive trends in the occurrence frequency and amount of the hourly precipitation extremes, including the TC-induced ones, are still concentrated over the PRD urban region, again suggesting a possible rainfall enhancement by the urban cluster.

The seven stations with a significant increasing trend of the EXHP's occurrence frequency (Fig. 7b) are selected to further examine their time series and change rates during 1971-2016. Similar analyses are also conducted for the pre- and post-rapid-urbanization 

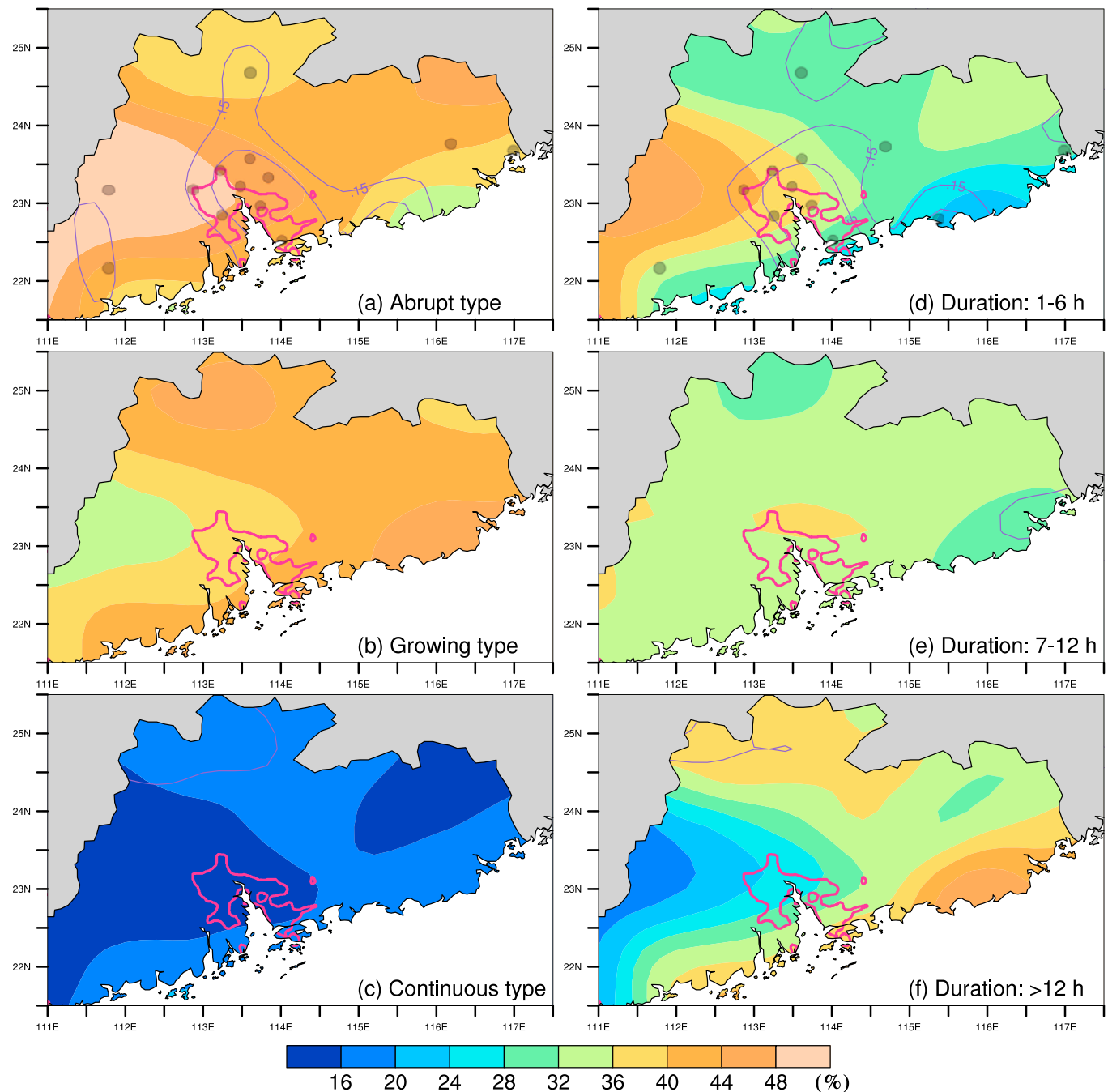

$\begin{array}{llllllllll}16 & 20 & 24 & 28 & 32 & 36 & 40 & 44 & 48 & (\%)\end{array}$

FIG. 9. Spatial distributions of the occurrence frequency (shading, \%) and trends (line, decade ${ }^{-1}$ ) of the categorized non-TC extreme rainfall events in 1971-2016: (a) abrupt type, (b) growing type, (c) continuous type, (d) short-duration type, (e) middle-duration type, and (f) long-duration type. Gray dots represent that the trends are significant at the $95 \%$ confidence level using the Mann-Kendall test. The occurrence frequency of an extreme precipitation type is the fractional contribution of this type to the total number of the extreme rainfall events.

periods, respectively, to further examine possible influence of the urban effect on the increasing EXHP. The comparison between the two periods at each station remains at least qualitatively unchanged when any year of the 1991-97 period is used as the demarcation point. Therefore, only the results using year 1994 as the demarcation point are presented herein. There are five stations (numbered 33, 34, 35, $39,40)$ are in the PRD urban region, and the other two (numbered 04 and 27) are in the north and east Guangdong, respectively. The five stations in the PRD urban region have either increase or decrease rates during the preurbanization era of 1971-2016 (orange lines; Figs. 8a-e). They all have increase rates during the rapid urbanization period (1994-2016) (red lines; Figs. 8a-e). The later 23-yr increase rates are about 1.44 to 2.36 times of the 46-yr (1971-2016) change rates. In contrast, at the other two stations away from the core PRD urban region the increase rates in the later 23-yr period are nearly the same (station 04 ; Fig. 8 f) or even smaller (station 27; Fig. 8g) compared to their counterparts in the preurbanization era. These results consistently support possible contribution of the PRD urbanization to more occurrences of hourly precipitation extremes.

Moreover, it is found that the statistically significant trends in the hourly precipitation extremes over the PRD urban region are more closely related to the abrupt type 

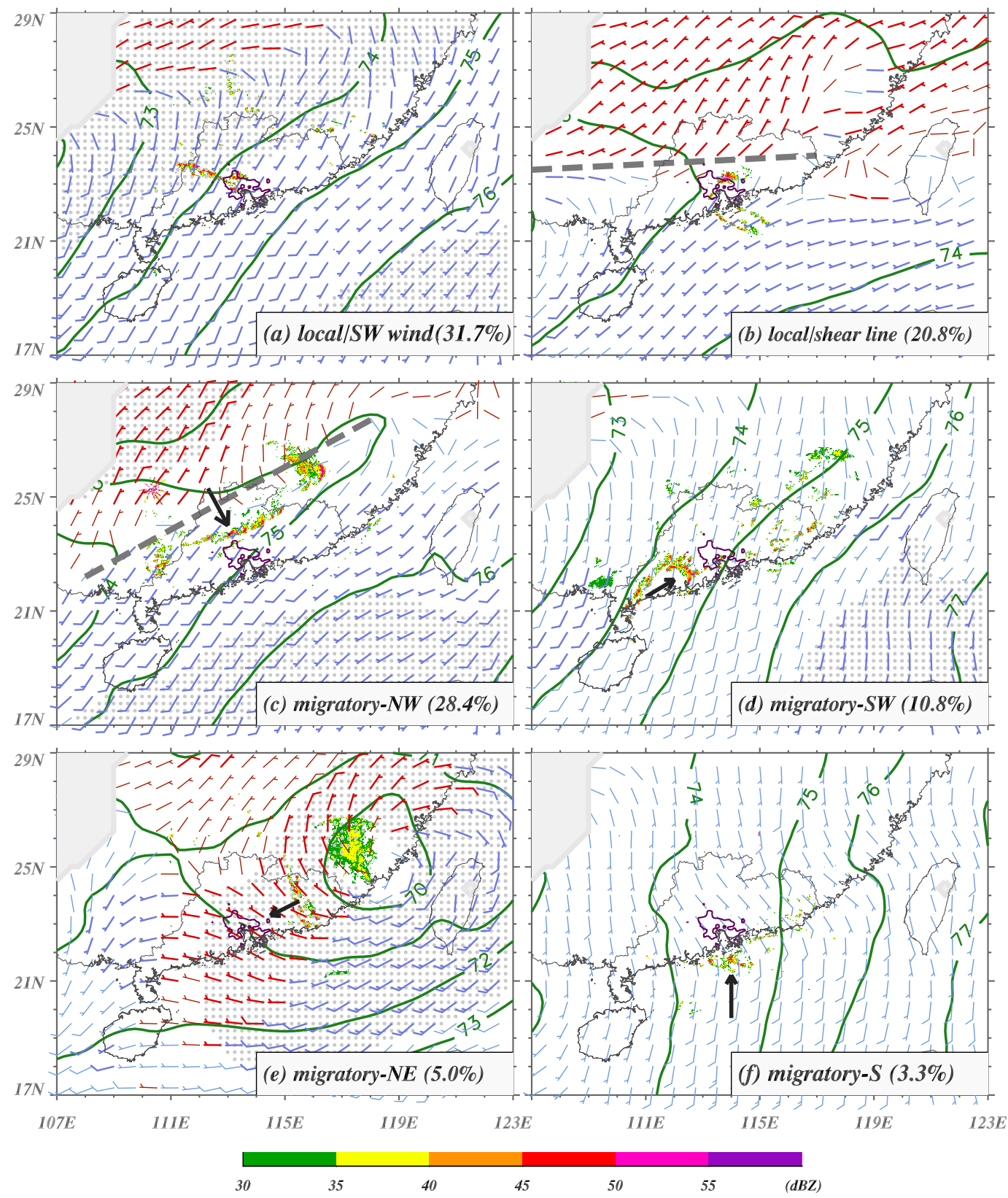

FIG. 10. Composite geopotential height (gpm; green lines) and wind barbs on $925 \mathrm{hPa}$ for the six types of the 2011-16 extreme rainfall events: (a) local/SW wind type, (b) local/shear line type, (c) migratory-NW type, (d) migratory-SW type, (e) migratory-NE type, and (f) migratory-S type. A full barb is $5 \mathrm{~m} \mathrm{~s}^{-1}$. The gray dots and bold wind barbs denote the values that are over the $90 \%$ confidence level using the Student's $t$ test. A typical rain storm of each extreme rainfall type is illustrated by radar reflectivity (color shadings), overlaid with a black arrow to denote its movement direction. The contribution of each type to the total number of the 2011-16 extremes (120) is labeled in parentheses. The gray-shaded regions denote the portions of isobaric surfaces underneath the ground.

extremes than the growing or continuous types (definitions given in Table 1). The abrupt type accounts for $44 \%$ of the total occurrence of the non-TC hourly extremes over the 61 stations in 1971-2016, the growing type is a close second $(40 \%)$, and the continuous type contributes the least $(16 \%)$. The spatial distributions of their fractional contributions (shadings in Figs. 9a-c) show that the abrupt type contributes the most in west Guangdong but relatively less along the coastline and in north Guangdong, while both the growing and the continuous types similarly show a largely opposite pattern to the abrupt type. Significant increase trends are observed only in the abrupt 

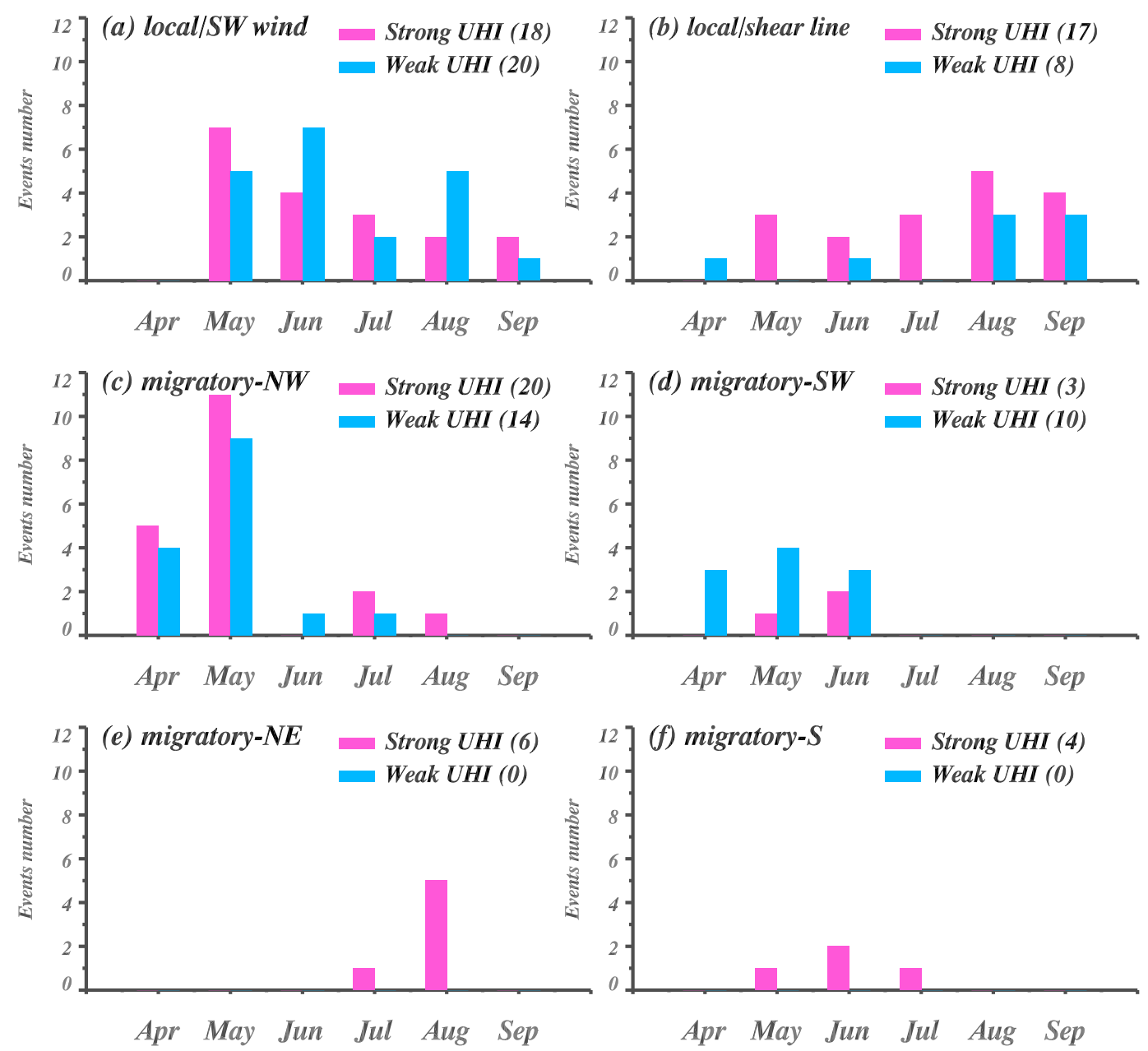

FIG. 11. Seasonality of the 2011-16 extreme rainfall events: (a) local/SW wind type, (b) local/shear line type, (c) migratory-NW type, (d) migratory-SW type, (e) migratory-NE type, and (f) migratory-S type. Pink and blue bars, respectively, represent the strong- and weak-UHI events. The number of events within each subtype is shown in parentheses.

type, mainly over the PRD urban region, with only a few scattered in other places of Guangdong (Fig. 9a).

Furthermore, when the non-TC extremes are classified by the time span of continuous rainfall $\left(>0.1 \mathrm{~mm} \mathrm{~h}^{-1}\right.$ with at most 1-h intervals), the short-, moderate-, and longduration types contribute $33.5 \%, 34.0 \%, 32.5 \%$, respectively, to the total occurrence of the extremes. Their corresponding spatial patterns (shadings in Figs. 9d-f) suggest that the short-duration type contributes more in west Guangdong (about $40 \%-48 \%$ ) than in other places of Guangdong especially along the coastline (mostly $<32 \%$ ); the long-duration ones show a nearly opposite feature; and the moderate-duration type accounts for about $32 \%-36 \%$ evenly over the entire analysis domain (Figs. 9d-f). Qualitatively similar to the abrupt type (Fig. 9a), significant increase trends of the short-duration events are observed and concentrated in the PRD urban region (Fig. 9d), while the longer-duration types show a lack of positive trends that are significant at the $95 \%$ confidence level.

The abovementioned results collectively suggest that the statistically significant increasing trends of hourly extreme precipitation in the PRD urban cluster are likely attributed to the rapid urbanization. Such trends are closely related to increasing occurrence frequency of short-duration, abrupt rainfall events, which may pose a greater threat to flash floods in the urban cluster and raise more challenge for accurate prediction.

\section{The 2011-16 EXREs}

As described in section 2c, totally 120 EXREs during 2011-16, each with at least one rainfall record 
Local/SW wind \& strong UHI (18)

(a) Time of occurrence

Ave. duration: $6.9 h \quad 00$ LST
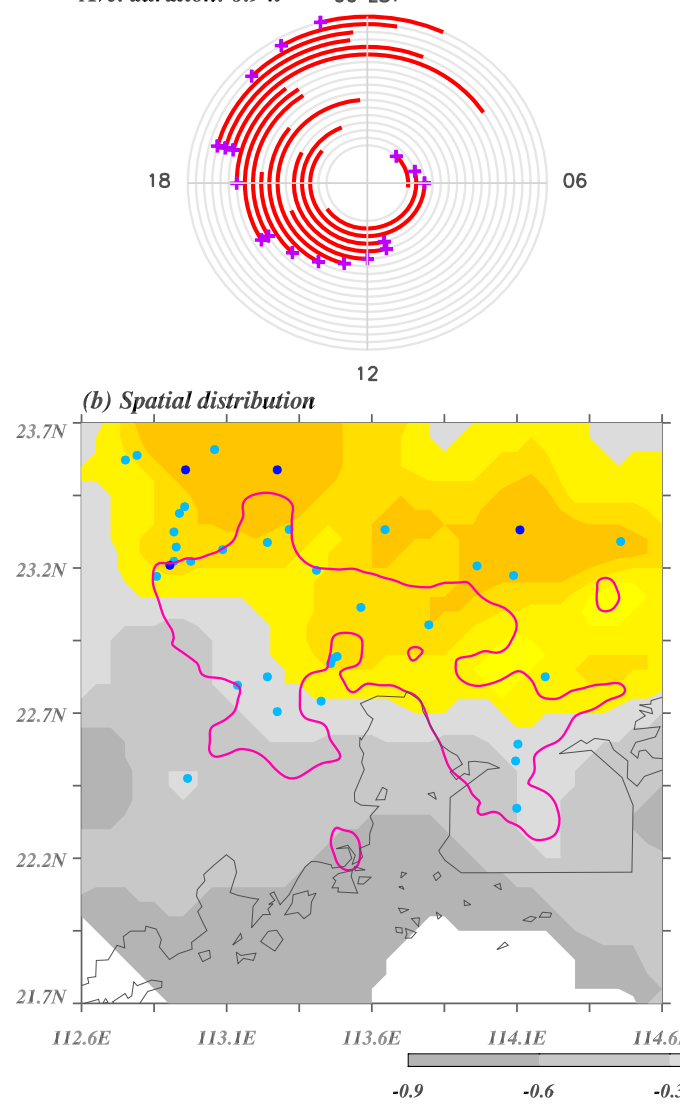

Local/SW wind \& weak UHI (20)

(c) Time of occurrence

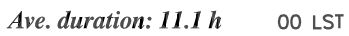

Ave. duration: $11.1 \mathrm{~h} \quad 00 \mathrm{LST}$

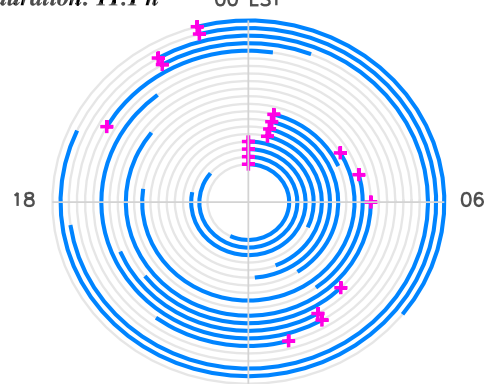

12

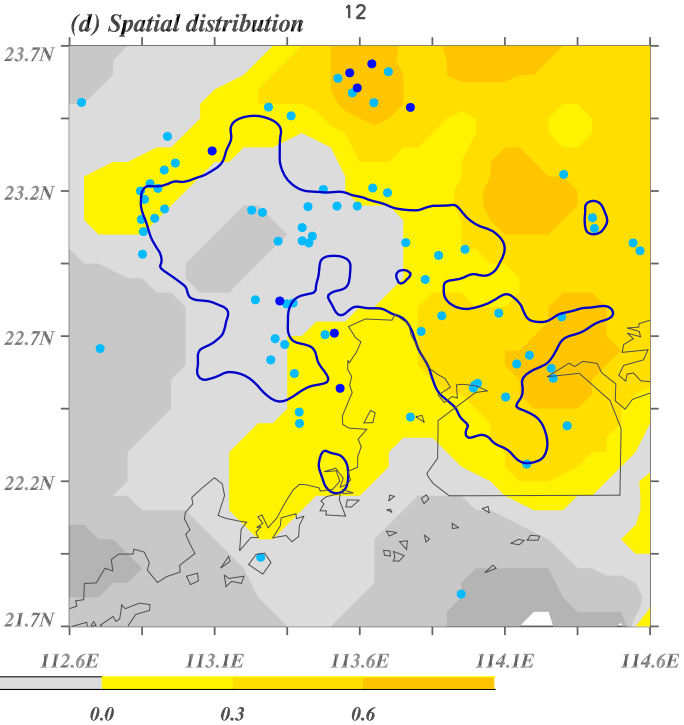

FIG. 12. (a) The timing of the local/SW wind type events with a strong UHI. The beginning time of each event is marked with a cross. The number of events and their average duration are also shown. (b) Composite spatial distribution of region-normalized rainfall amount (shading). Blue (dark blue) dots denote hourly rainfall records exceeding $60 \mathrm{~mm} \mathrm{~h}^{-1}$ occur once (more than once) in total among this type. (c),(d) As in (a),(b), respectively, but for the local/SW wind type events with a weak UHI.

of $>60 \mathrm{~mm} \mathrm{~h}^{-1}$ within the key region, are classified into six types (Table 2). This section first describes synoptic circulation and seasonality of each EXRE type. Then the two subgroups with the strong- and weak-UHI that belong to the same EXRE type are compared in terms of the temporal and spatial distributions of the precipitation.

\section{a. Synoptic circulation and seasonality}

Among the EXREs, 63 events (52.5\%) have locally developed rain systems, including 38 (31.7\%) under the influence of prevailing southwesterly winds in the lower troposphere and the planetary boundary layer (PBL) and $25(20.8 \%)$ accompanied by a synoptic shear line in the PBL over South China (Figs. 10a,b). These two types of locally developed rain systems are categorized into the local/SW wind and local/shear line types, respectively. The other 57 EXREs originated outside of the key region and moved from the northwest (28.4\%), southwest $(10.8 \%)$, northeast $(5.0 \%)$, or south $(3.3 \%)$ to influence the PRD urban region. These are categorized into the migratory-NW, migratory-SW, migratory-NE, or migratory-S types, respectively. The migratory-NW type is usually accompanied by a northeast-southwest oriented shear line in South China (Fig. 10c). In the migratory-NE type, a significant $\mathrm{TC}$ or its remnants is present around the Taiwan Strait, accompanied by a large precipitation area from where the migratory storm is separated (Fig. 10d). The migratory-SW and migratory-S types take place in prevailing southerly and southeasterly winds in the PBL (Figs. 10e,f).

Figure 11 shows the monthly occurrence frequency of the 2011-16 EXRE types, with a strong or weak PRD UHI, respectively. The two local types occur 

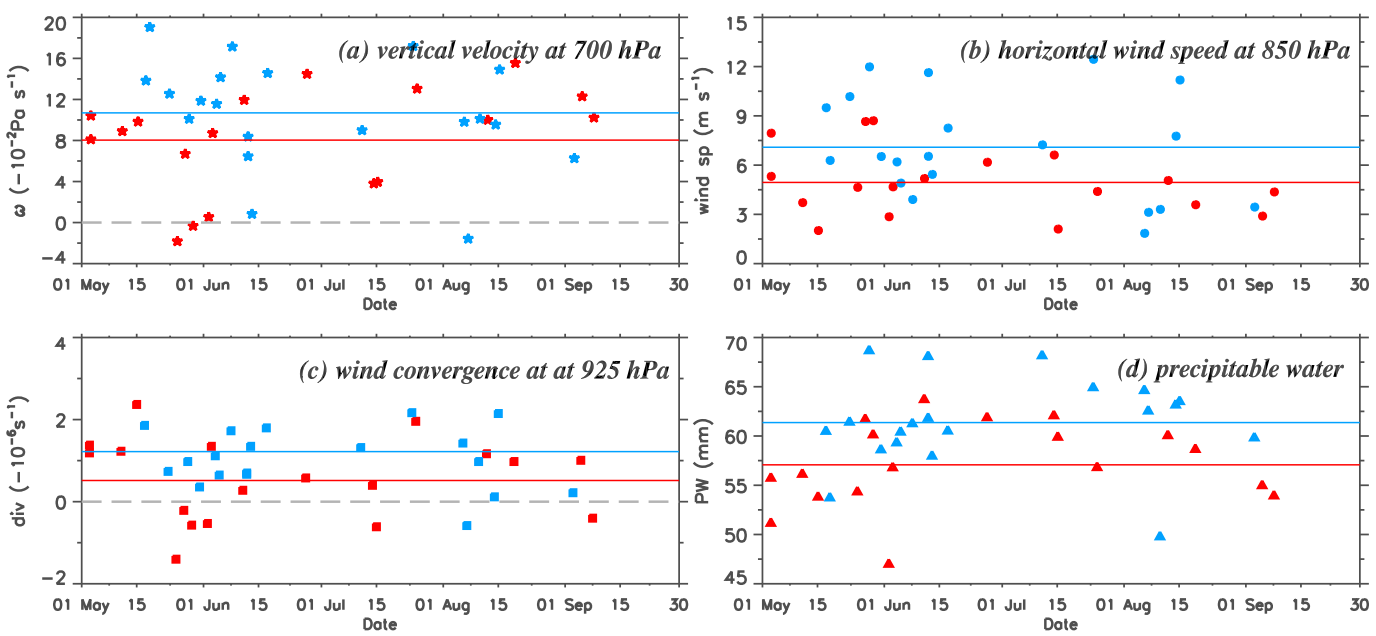

FIG. 13. (a) Vertical velocity $\left(-10^{-2} \mathrm{~Pa} \mathrm{~s}^{-1}\right)$ at $700 \mathrm{hPa}$, (b) horizontal wind speed $\left(\mathrm{m} \mathrm{s}^{-1}\right)$ at $850 \mathrm{hPa}$, (c) wind convergence $\left(-10^{-6} \mathrm{~s}^{-1}\right)$ at $925 \mathrm{hPa}$, and (d) precipitable water $(\mathrm{mm})$ averaged over the key region using the ERA-Interim reanalysis data. The red (blue) symbols represent the 18 (20) local/SW wind type EXREs with a strong (weak) UHI, and the red (blue) lines denote the corresponding average values.

more evenly from May to September than the migratory types. However, the local/SW wind type has about $60 \%$ (23 out of 38 ) in the middle-and-late stage of the presummer rainy season (May and June), while the local/shear line type has about $60 \%$ (15 out of 25 ) in August and September. The migratory-NW type mostly (85\%) takes place in April and May with the remaining $15 \%$ in June-August. The migratory-SW, migratory-NE, and migratory-S types are completely found in April-June, July-August, and May-July, respectively. The former four types have both strong- and weak-UHI events, without a remarkable difference between the strong and weak UHI events in the seasonality of each EXRE type. The migratory-NE and migratory-S types of the hourly precipitation extremes occur only with the strong UHI.

\section{b. Comparison between local EXREs with a strong and weak UHI}

The local/SW wind type with the strong UHI mostly (13 out of 18) initiates from the midday to afternoon and ends in the evening (Fig. 12a), producing extreme hourly rainfall $>60 \mathrm{~mm} \mathrm{~h}^{-1}$ mainly in the late afternoon. In contrast, with the weak UHI, this type of rain storms mostly (14 out of 20 ) initiates from late evening to nocturnal hours (Fig. 12c) and lasts significantly longer by average (11.3 vs $7.0 \mathrm{~h})$. This interesting contrast suggests possible difference in in large-scale environments for the two subgroups. Therefore, the key regionaveraged values of $700-\mathrm{hPa}$ vertical velocity, $850-\mathrm{hPa}$ wind speed, $925-\mathrm{hPa}$ wind convergence, and precipitable water, are compared among the local/SW wind type of EXREs (Fig. 13). The results suggest that the strong-UHI events tend to be associated with relatively slower upward motion, lower wind speed, weaker PBL wind convergence, and smaller amount of precipitable water (PW). These indicate relatively less favorable large-scale conditions for persistent convective development and could partially explain the shorter duration of the strong-UHI events. These contrasting results between the two subgroups suggest that the UHI thermal perturbation (e.g., Shepherd et al. 2002; Shepherd and Burian 2003) likely plays an important role in the convective initiation and development in the afternoon, when the UHIs are greater in clear and calm conditions (Landsberg 1981; Oke 1987; Yang et al. 2017) but the PBL southwesterly flows over South China tend to be weaker than in nocturnal hours (Du et al. 2014). The extreme hourly rainfall $\left(>60 \mathrm{~mm} \mathrm{~h}^{-1}\right)$ records of the local/SW wind type (blue dots in Figs. 12b,d) are observed mainly within the urban cluster and close (within about $50 \mathrm{~km}$ ) to its northern boundary regardless of the UHI strength, while some extreme rainfall records in the weak UHI cases are located near the coastline.

The strong-UHI subgroup of the local/shear line type mainly (13 out of 17 events) initiates and develops during the daytime particularly in the afternoonto-evening hours (Fig. 14a). This subgroup has the hourly extremes and rainfall accumulation mostly over the inland portion of the PRD urban cluster (Fig. 14b), where the UHI is most intense (Fig. 4a). In contrast the weak-UHI subgroup has 3 out of 8 events initiating in the nocturnal, 1 in the morning, and 4 in the afternoon (Fig. 14c). The weak-UHI subgroup produces rainfall mostly near the coastline (Fig. 14d), attributable to more (less) favorable 
Local/shear line \& strong UHI (17)

(a) Time of occurrence

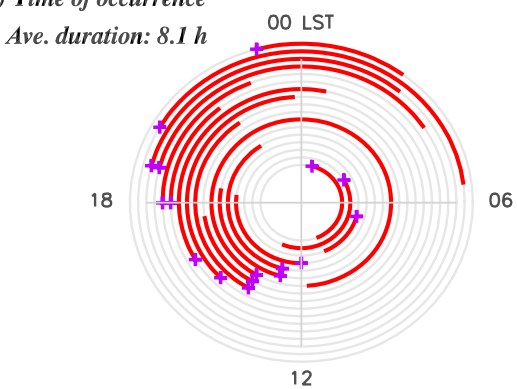

(b) Spatial distribution

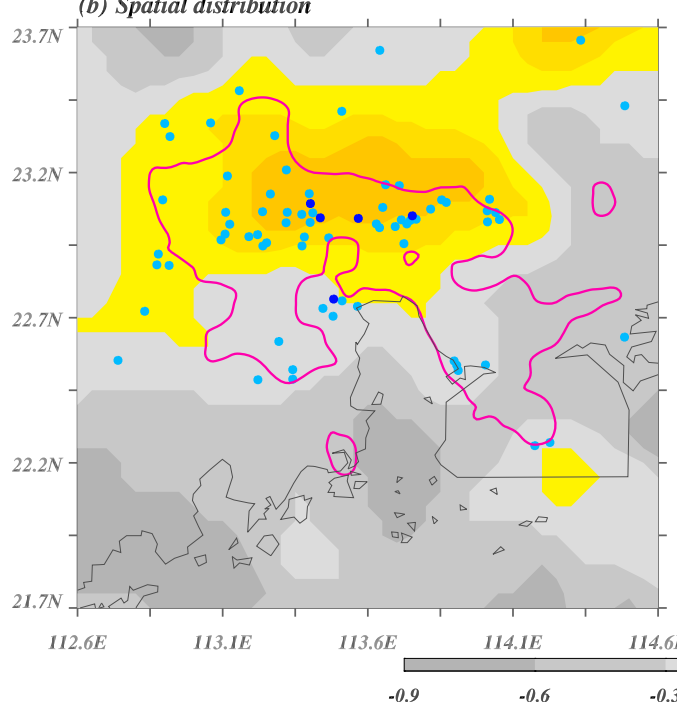

Local/shear line \& weak UHI (8)

(c) Time of occurrence

Ave. duration: $11.6 \mathrm{~h}$

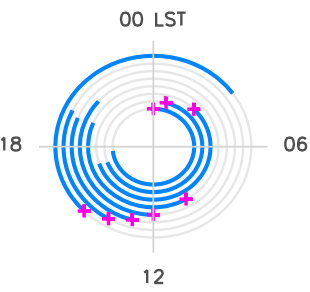

FIG. 14. As in Fig. 12, but for the local/shear line type of the 2011-16 EXREs.

thermodynamic conditions [i.e., more (less) moisture and larger (smaller) convective available potential energy] to the south/north of the shear line (Fig. 10b). The different features in the temporal and spatial distributions of the two subgroups support possible convective intensification and rainfall enhancement by the strong UHI over the inland PRD urban region for the local/shear line type EXREs.

In addition to the UHI effect, sea breezes could also play an important role in convection development and rainfall production over the PRD region; for example, a close association between sea breezes and inland propagation of warm-season rainfall over the PRD coastal region during the daytime was noticed (Chen et al. 2016; Z. N. Jiang et al. 2017). Moreover, extreme precipitation events over coastal South China can be influenced by the trumpet-shaped topography of the PRD (Huang et al. 2019) and the coastal mountains (Wang et al. 2014; Wu and Luo 2016). Interactions between sea breezes, UHI-induced circulation, largerscale southwesterly air flows (Fig. 10a), and topography, as well as their influence on the timing, location, and evolution of rain storms in the local/SW wind type of EXREs deserve further study.

\section{c. Comparison between migratory EXREs with a strong and weak UHI}

For the migratory EXRE types, a strong PRD UHI is expected to impact the rainfall intensity and distribution over the key region rather than the timing of these EXRE types. Visual examination of radar reflectivity animation indeed suggests notable intensification of radar reflectivity when the rain storms approach the strong-UHI region especially over the inland PRD, which is not observed in the weak-UHI cases. This expectation is also confirmed by examining the rainfall distribution. Therefore, this subsection will discuss mostly the spatial distributions of extreme hourly rainfall records and accumulated rainfall amounts, although the timing of the EXREs will still be shown.

For the migratory-NW type, which accounts for $60 \%$ of the total number of the migratory EXREs, both the hourly precipitation extremes and rainfall 
Migratory-NW \& strong UHI (20)

(a) Time of occurrence

Ave. duration: $12.1 \mathrm{~h} \quad 00$ LST

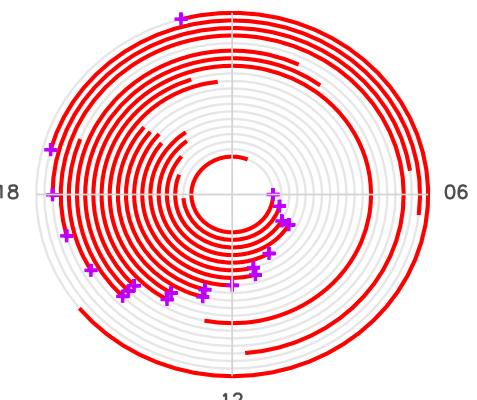

(b) Spatial distribution

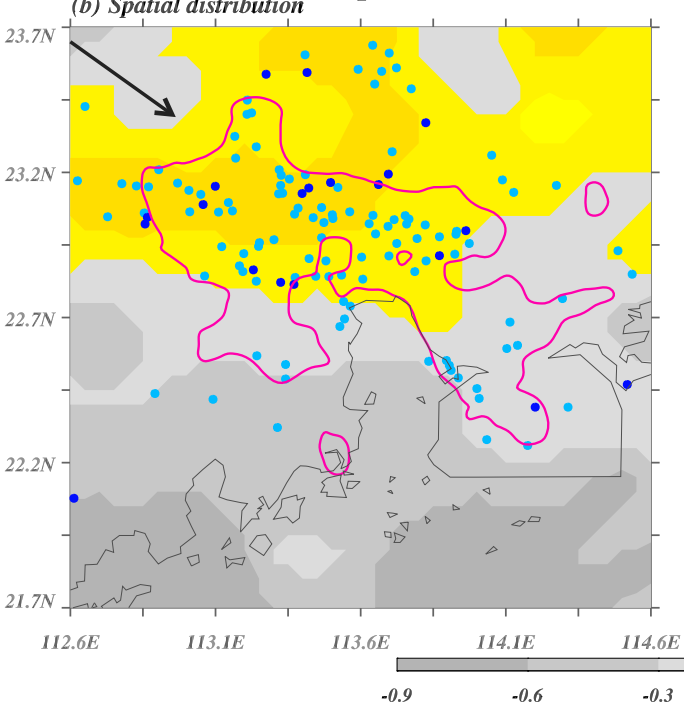

Migratory-NW \& weak UHI (14)

(c) Time of occurrence

Ave. duration: $13.7 \mathrm{~h}$

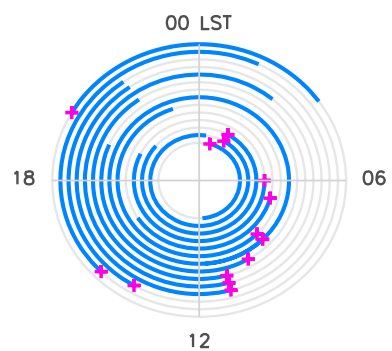

(d) Spatial distribution

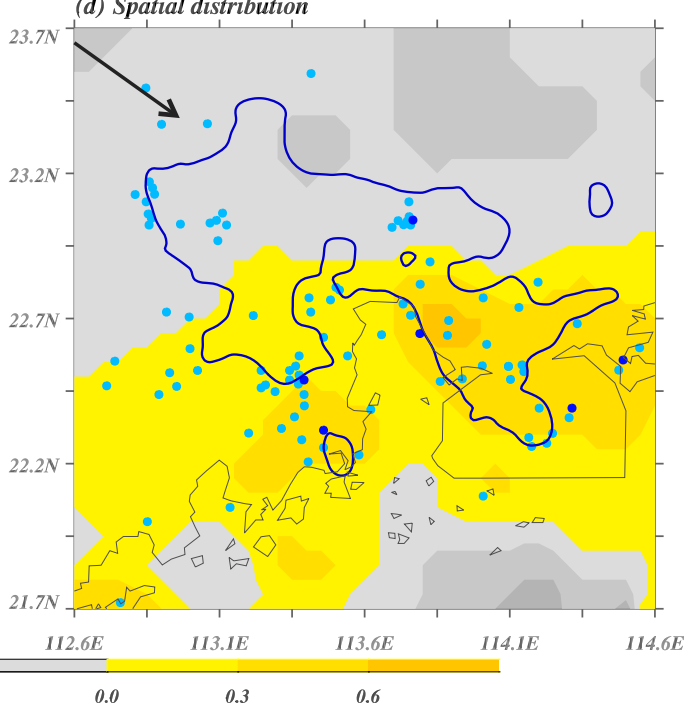

FIG. 15. As in Fig. 12, but for the migratory-NW type of the 2011-16 EXREs. The arrow in (c) and (d) denotes the movement direction of the extreme-rain-producing storm.

accumulation tend to concentrate over the inland portion of the PRD urban cluster in the strong-UHI subgroup (Fig. 15b), while those of the weak-UHI subgroup are contrastingly situated near the coastline with smaller rainfall amounts in the inland urban region (Fig. 15d). The larger rainfall amounts near the coastline could be attributed to higher equivalent potential temperature $\left(\theta_{e}\right)$ of air masses near the coastline in the weakUHI cases (not shown).

The migratory-SW type consists of only 3 EXREs with strong UHI. Despite of the small number of events, it is still noted that both the hourly precipitation extremes and rainfall accumulation are mainly concentrated over the urban cluster (Fig. 16c). In contrast the 10 migratory-SW EXREs with weak UHI have the hourly extremes mainly distributed over the southwest coastal area (Fig. 16d).

All the 6 migratory-NE EXREs are accompanied by a strong UHI and their extreme hourly precipitation records are mostly located over the urban cluster
(Fig. 17b). The rain storms in these cases intensify immediately when enter the urban cluster and weaken quite rapidly when move out from the southwest boundary of the urban region. Moreover, three extra rainfall events that similarly have the rain storm moving out from a TC or its remnant centered around the Taiwan Strait to influence the PRD region are found. These three events have weak UHI and do not produce hourly precipitation $>60 \mathrm{~mm} \mathrm{~h}^{-1}$. The radar animation (not shown) suggests that the rain storms weaken or dissipate when they pass the PRD urban region, opposite to the evolution of rain storms in the 6 strongUHI cases.

The 4 migratory-S EXREs are also accompanied by a strong UHI. Examination of the radar animation (not shown) suggests convective intensification when the storms move over the UHI. However, the storms produce accumulative rainfall mainly over the coastal region, with a secondary rainfall center over the northwest PRD urban region (Fig. 17d). 
Migratory-SW \& strong UHI (3)

(a) Time of occurrence

Ave. duration: $8.7 \mathrm{~h}$

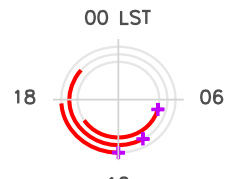

12

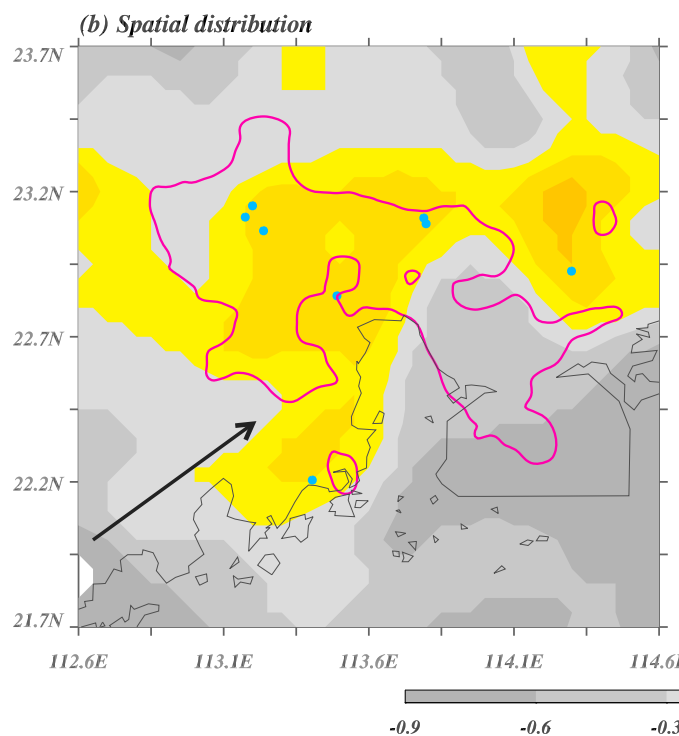

Migratory-SW \& weak UHI (10)

(c) Time of occurrence

Ave. duration: $13.4 \mathrm{~h}$

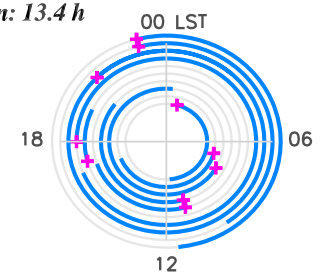

(d) Spatial distribution

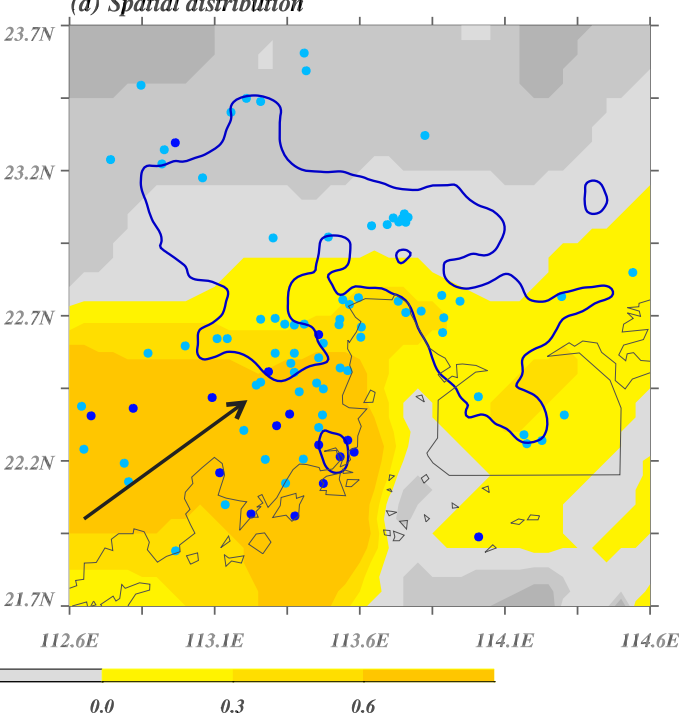

FIG. 16. As in Fig. 12, but for the migratory-SW type of the 2011-16 EXREs. The arrow in (c) and (d) denotes the movement direction of the extreme-rain-producing storm.

Stronger evidence of rainfall intensification by the UHI is limited by the small number of this EXRE type.

\section{Summary and conclusions}

This study investigates the changes in extreme hourly precipitation in coastal areas of South China, focusing on its relationship with the PRD urbanization through: 1) exploring long-term changes of hourly extremes (defined by the 95th percentile) using gauge-based hourly precipitation observations at 61 national-level surface stations over 46 years (1971-2016); and 2) analyzing the 120 extreme rainfall events (with at least one record of $>60 \mathrm{~mm} \mathrm{~h}^{-1}$ hourly rainfall in the key region) in 2011-16 using observations collected by densely distributed AWSs and radar network in coastal South China. The major findings are summarized as follows:

1) Statistically significant increase of hourly precipitation intensity leads to higher annual amounts of both total and extreme precipitation over the PRD urban cluster in the rapid urbanization period (about 1994-2016) than during the preurbanization era (1971-about 1993), suggesting a possible link of rainfall enhancement to the rapid urbanization. This tends to change the pattern of climatological-mean precipitation distribution as the urban cluster is situated among the three centers of climatological-mean precipitation amount over coastal South China and tends to connect the centers.

2) Those urbanization-induced positive trends of the extreme hourly rainfall amount and frequency over PRD are found in the majority of stations over the PRD when the TC-produced extreme rainfall records are excluded. The trends are more closely related to more frequent occurrence of the short-duration $(\leq 6 \mathrm{~h})$, abrupt rainfall events, than the longer-duration, continuous, or growing rainfall events.

3) The 120 EXREs in 2011-16 consist of 67 (53) cases with a strong (weak) UHI. They are categorized into six types according to the originating location and movement of the extreme-rain-producing storms, namely, the local $/ \mathrm{SW}$ wind $(31.7 \%)$, local $/$ shear 
Migratory-NE \& strong UHI (6)

(a) Time of occurrence

Ave. duration: $9.8 \mathrm{~h}$

18

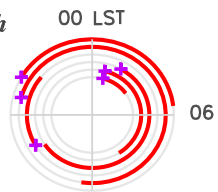

(b) Spatial distribution

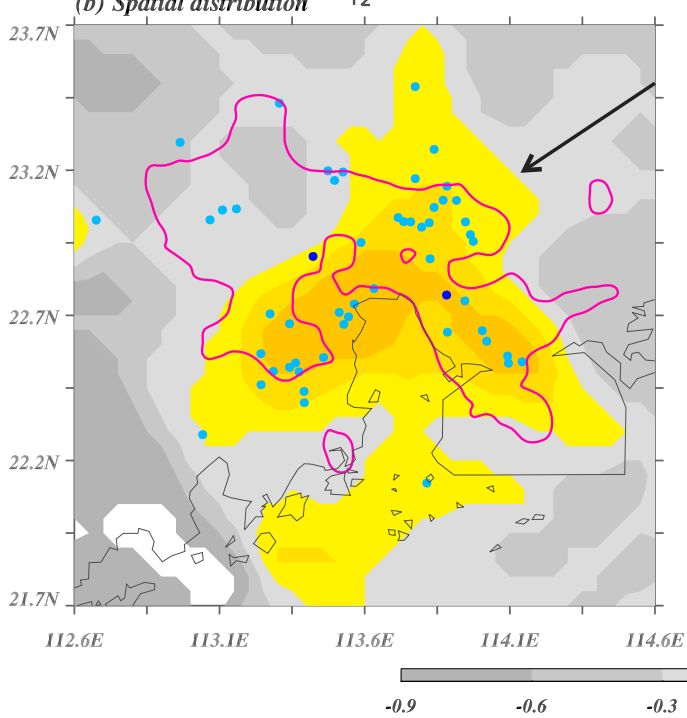

Migratory-S \& strong UHI (4)

(c) Time of occurrence

Ave. duration: $12.2 \mathrm{~h} \quad 00 \mathrm{LST}$

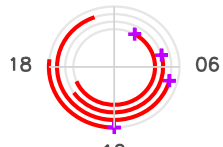

(d) Spatial distribution

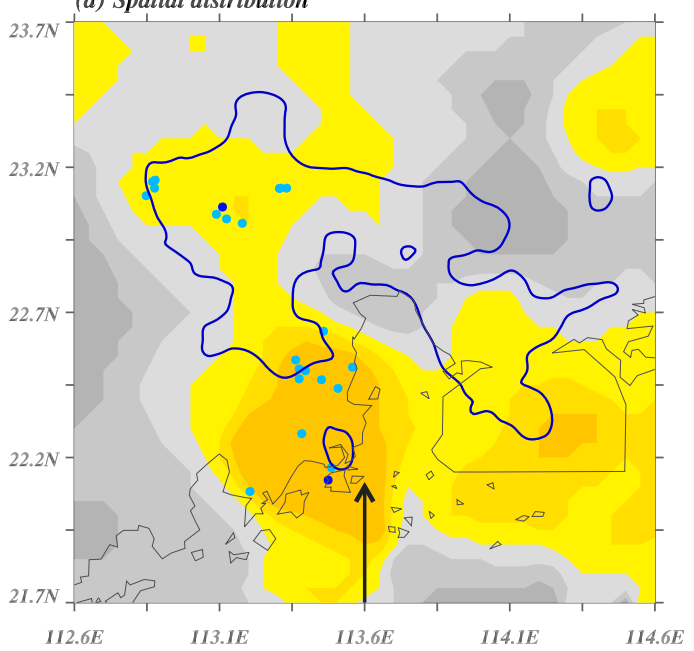

FIG. 17. As in Fig. 12, but for the (a),(b) migratory-NE type and (c),(d) migratory-S type of the 2011-16 EXREs. Both types only have strong-UHI events. The arrow in (c) and (d) denotes the movement direction of the extremerain-producing storm.

line $(20.8 \%)$, and migratory-NW, migratory-SW, migratory-NE, or migratory-S types $(28.3 \%, 10.8 \%$, $5.0 \%, 3.3 \%)$. Irrespective of synoptic conditions and seasons (April-September) in which the EXREs take place, rainfall intensification by the strong UHI is noticeable in all the six types, especially over the inland urban region where the UHI intensity is strongest, because of the strong UHI-induced larger CAPE to feed the rain storms. The UHI thermal perturbation probably plays an important role in the convective initiation and intensification of the locally developed rain storms in the afternoon.

This study provides observed evidence of hourly rainfall intensification over the PRD urban cluster, especially its inland portion, in a large ensemble of EXREs under various synoptic conditions, consistent with the findings from the long-term trend analysis. The results build a scientific basis for future in-depth analysis and modeling studies to better understand the individual and combined impacts of local urban environment and global warming on the change of hourly precipitation extremes over the coastal South China during the past decades. Physical mechanisms about the impacts of urban cluster on evolution of extremerain-producing storms (e.g., the UHI-induced destabilization, anthropogenic aerosol emissions) can also be better understood using high-resolution modeling experiments.

Acknowledgments. This research is supported by National (Key) Basic Research and Development Program of China (2018YFC1507400), The National Natural Science Foundation of China (41775050), and the Basic Research and Operation Funding of Chinese Academy of Meteorological Sciences (CAMS) (2017Z006). We also acknowledge the support from the National Center for Atmospheric Research (NCAR) Water System and the USDA-NIFA Agriculture and Food Research Initiative (Awards 201567003-23508 and 2015-67003-23460). We thank Dr. Fumin Ren (CAMS) for help on using OSAT to identify the TC-induced precipitation and Prof. DaLin Zhang (University of Maryland) for helpful discussions. The land-use data were downloaded from the Resources and Environment Scientific Data Center, Chinese Academy of Sciences (http://www.resdc.cn/ data.aspx?DATAID $=98$ ). 


\section{REFERENCES}

Alexander, L. V., and J. M. Arblaster, 2009: Assessing trends in observed and modelled climate extremes over Australia in relation to future projections. Int. J. Climatol., 29, 417-435, https://doi.org/10.1002/joc.1730.

Bell, T. L., D. Rosenfeld, and K.-M. Kim, 2009: Weekly cycle of lightning: Evidence of storm invigoration by pollution. Geophys. Res. Lett., 36, L23805, https://doi.org/10.1029/2009GL040915.

Bornstein, R. D., and Q. Lin, 2000: Urban heat islands and summertime convective thunderstorms in Atlanta: Three case studies. Atmos. Environ., 34, 507-516, https://doi.org/10.1016/ S1352-2310(99)00374-X.

Chang, C. P., Y. Lei, C.-H. Sui, X. Lin, and F. Ren, 2012: Tropical cyclone and extreme rainfall trends in East Asian summer monsoon since mid-20th century. Geophys. Res. Lett., 39, L18702, https://doi.org/10.1029/2012GL052945.

Chen, X., F. Zhang, and K. Zhao, 2016: Diurnal variations of the land-sea breeze and its related precipitation over South China. J. Atmos. Sci., 73, 4793-4815, https://doi.org/10.1175/ JAS-D-16-0106.1.

Craig, K., and R. Bornstein, 2002: MM5 simulations of urban induced convective precipitation over Atlanta. Preprints, Fourth Conf. on the Urban Environment, Norfolk, VA, Amer. Meteor. Soc., 1.3, https://ams.confex.com/ams/AFMAPUE/techprogram/ paper_38803.html.

Dee, D. P., and Coauthors, 2011: The ERA-Interim reanalysis: Configuration and performance of the data assimilation system. Quart. J. Roy. Meteor. Soc., 137, 553-597, https://doi.org/10.1002/qj.828.

Ding, Y. H., 1994: Monsoons over China. Kluwer Academic Publishers, $419 \mathrm{pp}$.

Donat, M. G., A. L. Lowry, L. V. Alexander, P. A. O'Gorman, and N. Maher, 2016: More extreme precipitation in the world's dry and wet regions. Nat. Climate Change, 6, 508-513, https:// doi.org/10.1038/nclimate2941.

Dou, J., Y. Wang, R. Bornstein, and S. Miao, 2015: Observed spatial characteristics of Beijing urban climate impacts on summer thunderstorms. J. Appl. Meteor. Climatol., 54, 94-105, https://doi.org/10.1175/JAMC-D-13-0355.1.

Du, Y., Q. Zhang, Y. Chen, Y. Zhao, and X. Wang, 2014: Numerical simulations of spatial distributions and diurnal variations of lowlevel jets in China during early summer. J. Climate, 27, 57475767, https://doi.org/10.1175/JCLI-D-13-00571.1.

Gong, P., and Coauthors, 2013: Finer resolution observation and monitoring of global land cover: First mapping results with Landsat TM and ETM+ data. Int. J. Remote Sens., 34, 26072654, https://doi.org/10.1080/01431161.2012.748992.

Grimm, N. B., S. H. Faeth, N. E. Golubiewski, C. L. Redman, J. Wu, X. Bai, and J. M. Briggs, 2008: Global change and the ecology of cities. Science, 319, 756-760, https://doi.org/10.1126/ science. 1150195.

Guangdong Statistical Bureau, 2016: Statistical Yearbook of Guangdong Province (updated yearly). Accessed 15 November 2017, http://stats.gd.gov.cn/gdtjnj/index.html.

Guo, J., and Coauthors, 2017: Declining frequency of summertime local-scale precipitation over eastern China from 1970 to 2010 and its potential link to aerosols. Geophys. Res. Lett., 44, 57005708, https://doi.org/10.1002/2017GL073533.

Guo, X., D. Fu, and J. Wang, 2006: Mesoscale convective precipitation system modified by urbanization in Beijing city. Atmos. Res., 82, 112-126, https://doi.org/10.1016/j.atmosres.2005.12.007.

Hallegatte, S., C. Green, R. J. Nicholls, and J. Corfee-Morlot, 2013: Future flood losses in major coastal cities. Nat. Climate Change, 3, 802-806, https://doi.org/10.1038/nclimate1979.
Hjelmfelt, M. R., 1982: Numerical simulation of the effects of St. Louis on mesoscale boundary-layer airflow and vertical air motion: Simulations of urban vs. nonurban effects. J. Appl. Meteor., 21, 1239-1257, https://doi.org/10.1175/ 1520-0450(1982)021<1239:NSOTEO > 2.0.CO;2.

Huang, L., Y. Luo, and D.-L. Zhang, 2018: The relationship between anomalous presummer extreme rainfall over south China and synoptic disturbances. J. Geophys. Res. Atmos., 123, 3395-3413, https://doi.org/10.1002/2017JD028106.

Huang, Y., Y. Liu, Y. Liu, H. Li, and J. C. Knievel, 2019: Mechanisms for a record-breaking rainfall in the coastal metropolitan city of Guangzhou, China: Observation analysis and nested very large eddy simulation with the WRF Model. J. Geophys. Res., 124, 1370-1391, https://doi.org/10.1029/2018JD029668.

Huff, F. A., and J. L. Vogel, 1978: Urban, topographic, and diurnal effects on rainfall in the St. Louis region. J. Appl. Meteor., 17, 565-577, https://doi.org/10.1175/1520-0450(1978)017<0565: UTADEO $>2.0 . \mathrm{CO} ; 2$.

Jiang, Z. H., F. Huo, H. Ma, J. Song, and A. Dai, 2017: Impact of Chinese urbanization and aerosol emissions on the East Asian summer monsoon. J. Climate, 30, 1019-1039, https://doi.org/ 10.1175/JCLI-D-15-0593.1.

Jiang, Z. N., D.-L. Zhang, R. Xia, and T. Qian, 2017: Diurnal variations of presummer rainfall over southern China. J. Climate, 30, 755-773, https://doi.org/10.1175/JCLI-D-15-0666.1.

Jin, M., and J. M. Shepherd, 2008: Aerosol relationships to warm season clouds and rainfall at monthly scales over east China: Urban land versus ocean. J. Geophys. Res., 113, D24S90, https://doi.org/10.1029/2008JD010276.

Kendall, M. G., 1975: Rank Correlation Methods. Griffin \& Co., 196 pp.

Landsberg, H. E., 1981: The Urban Climate. Academic Press, 275 pp.

Li, C. Y., and W. Zhou, 2015: Interdecadal changes in summertime tropical cyclone precipitation over southeast China during 1960-2009. J. Climate, 28, 1494-1509, https://doi.org/10.1175/ JCLI-D-14-00246.1.

- — C. C. M. Shun, and T. C. Lee, 2017: Change in destructiveness of landfalling tropical cyclones over China in recent decades. J. Climate, 30, 3367-3379, https://doi.org/ 10.1175/JCLI-D-16-0258.1.

Li, J., R. Yu, and T. Zhou, 2008: Seasonal variation of the diurnal cycle of rainfall in southern contiguous China. J. Climate, 21, 6036-6043, https://doi.org/10.1175/2008JCLI2188.1.

Li, W., S. Chen, G. Chen, W. Sha, C. Luo, Y. Feng, Z. Wen, and B. Wang, 2011: Urbanization signatures in strong versus weak precipitation over the Pearl River delta metropolitan regions of China. Environ. Res. Lett., 6, 034020, https://doi.org/ 10.1088/1748-9326/6/3/034020.

Li, Z., X. Deng, F. Wu, and S. S. Hasan, 2015: Scenario analysis for water resources in response to land use change in the middle and upper reaches of the Heihe River Basin. Sustainability, 7, 3086-3108, https://doi.org/10.3390/su7033086.

Liang, P., and Y. Ding, 2017: The long-term variation of extreme heavy precipitation and its link to urbanization effects in Shanghai during 1916-2014. Adv. Atmos. Sci., 34, 321-334, https://doi.org/10.1007/s00376-016-6120-0.

Liu, J., and Coauthors, 2014: Spatiotemporal characteristics, patterns, and causes of land-use changes in China since the late 1980s. J. Geogr. Sci., 24, 195-210, https://doi.org/10.1007/ s11442-014-1082-6.

Liu, X., Y. Luo, Z. Guan, and D.-L. Zhang, 2018: An extreme rainfall event in coastal South China during SCMREX-2014: 
Formation and roles of rainband and echo trainings. J. Geophys. Res. Atmos., 123, 9256-9278, https://doi.org/10.1029/ 2018JD028418.

Lomax, R. G., and D. L. Hahs-Vaughn, 2007: Statistical Concepts: A Second Course. $532 \mathrm{pp}$.

Luo, Y., M. Wu, F. Ren, J. Li, and W. Wong, 2016: Synoptic situations of extreme hourly precipitation over China. J. Climate, 29, 8703-8719, https://doi.org/10.1175/JCLI-D-16-0057.1.

Mann, H. B., 1945: Nonparametric tests against trend. Econometrica, 13, 245-259, https://doi.org/10.2307/1907187.

Miao, S., F. Chen, Q. Li, and S. Fan, 2011: Impacts of urban processes and urbanization on summer precipitation: A case study of heavy rainfall in Beijing on 1 August 2006. J. Appl. Meteor Climatol., 50, 806-825, https://doi.org/10.1175/2010JAMC2513.1.

Min, S. K., X. Zhang, F. W. Zwiers, and G. C. Hegerl, 2011: Human contribution to more-intense precipitation extremes. Nature, 470, 378-381, https://doi.org/10.1038/nature09763.

Niyogi, D., P. Pyle, M. Lei, S.P. Arya, C. M. Kishtawal, M. Shepherd, F. Chen, and B. Wolfe, 2011: Urban modification of thunderstorms-An observational storm climatology and model case study for the Indianapolis urban region. J. Appl. Meteor. Climatol., 50, 1129-1144, https://doi.org/10.1175/2010JAMC1836.1.

Ntelekos, A. A., J. A. Smith, L. Donner, J. D. Fast, W. I. Gustafson Jr., E. G. Chapman, and W. F. Krajewski, 2009: The effects of aerosols on intense convective precipitation in the northeastern United States. Quart. J. Roy. Meteor. Soc., 135, 1367-1394, https://doi.org/10.1002/qj.476.

Oke, T. R., 1987: Boundary Layer Climates. 2nd ed. Methuen Co. $435 \mathrm{pp}$.

Pfahl, S., P. A. O'Gorman, and E. M. Fischer, 2017: Understanding the regional pattern of projected future changes in extreme precipitation. Nat. Climate Change, 7, 423-427, https://doi.org/ 10.1038/nclimate3287.

Ramage, C. S., 1952: Variation of rainfall over South China through the wet season. Bull. Amer. Meteor. Soc., 33, 308-311, https://doi.org/10.1175/1520-0477-33.7.308.

Ren, F., G. Wu, W. Dong, X. Wang, Y. Wang, W. Ai, and W. Li, 2006: Changes in tropical cyclone precipitation over China. Geophys. Res. Lett., 33, L20702, https://doi.org/10.1029/ 2006GL027951.

_- Y. Wang, X. Wang, and W. Li, 2007: Estimating tropical cyclone precipitation from station observations. Adv. Atmos. Sci., 24, 700-711, https://doi.org/10.1007/s00376-007-0700-y.

_ , J. Liang, G. Wu, W. Dong, and X. Yang, 2011: Reliability analysis of climate change of tropical cyclone activity over the western North Pacific. J. Climate, 24, 5887-5898, https:// doi.org/10.1175/2011JCLI3996.1.

Ren, G., and Y. Zhou, 2014: Urbanization effect on trends of extreme temperature indices of national stations over Mainland China, 1961-2008. J. Climate, 27, 2340-2360, https://doi.org/ 10.1175/JCLI-D-13-00393.1.

Rosenfeld, D., 2000: Suppression of rain and snow by urban and industrial air pollution. Science, 287, 1793-1806, https:// doi.org/10.1126/science.287.5459.1793.

Seneviratne, S. I., and Coauthors, 2012: Changes in climate extremes and their impacts on the natural physical environment. Managing the Risks of Extreme Events and Disasters to Advance Climate Change Adaptation, C. B. Field et al., Eds., Cambridge University Press, 109-230.

- M. G. Donat, A. J. Pitman, R. Knutti, and R. L. Wilby, 2016: Allowable $\mathrm{CO}_{2}$ emissions based on regional and impactrelated climate targets. Nature, 529, 477-483, https://doi.org/ 10.1038/nature16542.
Shepherd, J. M., 2005: A review of current investigations of urbaninduced rainfall and recommendations for the future. Earth Interact., 9, https://doi.org/10.1175/EI156.1.

, and S. J. Burian, 2003: Detection of urban-induced rainfall anomalies in a major coastal city. Earth Interact., 7, https:// doi.org/10.1175/1087-3562(2003)007<0001:DOUIRA >2.0.CO;2.

$\longrightarrow$, H. Pierce, and A. J. Negri, 2002: Rainfall modification by major urban areas: Observations from spaceborne rain radar on the TRMM satellite. J. Appl. Meteor., 41, 689-701, https://doi.org/ 10.1175/1520-0450(2002)041<0689:RMBMUA > 2.0.CO;2.

Siler, N., and G. Roe, 2014: How will orographic precipitation respond to surface warming? An idealised thermodynamic perspective. Geophys. Res. Lett., 41, 2606-2613, https:// doi.org/10.1002/2013GL059095.

UN Department of Economic and Social Affairs, Population Division, 2011: Comprehensive tables. Vol. I, World Population Prospects: The 2010 Revision, United Nations, ST/ESA/SER.A/313, 503 pp., https://www.un.org/en/development/ desa/population/publications/pdf/trends/WPP2010/WPP2010_ Volume-I_Comprehensive-Tables.pdf.

Wang, X. H., P. F. Xiao, X. Feng, and H. Li, 2013: Extraction of large-scale urban area information in China using DMSP/OLS nighttime light data. Remote Sens. Land Resour., 25, 159-164, https://doi.org/10.6046/gtzyyg.2013.03.26.

Wang, H., Y. L. Luo, and B. J.-D. Jou, 2014: Initiation, maintenance, and properties of convection in an extreme rainfall event during SCMREX: Observational analysis. J. Geophys. Res., 119, 13206-13 232, https://doi.org/10.1002/2014JD022339.

Westra, S., L. V. Alexander, and F. W. Zwiers, 2013: Global increasing trends in annual maximum daily precipitation. $J$. Climate, 26, 3904-3918, https://doi.org/10.1175/JCLI-D-12-00502.1.

Wu, M., and Y. Luo, 2016: Mesoscale observational analysis of lifting mechanism of a warm-sector convective system producing the maximal daily precipitation in China mainland during pre-summer rainy season of 2015. J. Meteor. Res., 30, 719-736, https://doi.org/10.1007/s13351-016-6089-8.

Yang, P., G. Y. Ren, and P. Yan, 2017: Evidence for a strong association of short-duration intense rainfall with urbanization in the Beijing urban area. J. Climate, 30, 5851-5870, https:// doi.org/10.1175/JCLI-D-16-0671.1.

Yu, Q., 2007: Inter-annual variability of precipitation urbanization effects in Beijing. Prog. Nat. Sci., 17, 632-638.

Yu, R., T. Zhou, A. Xiong, Y. Zhu, and J. Li, 2007: Diurnal variations of summer precipitation over contiguous China. Geophys. Res. Lett., 34, L01704, https://doi.org/10.1029/ 2006GL028129.

Yuan, W., R. Yu, M. Zhang, W. Lin, H. Chen, and J. Li, 2012: Regimes of diurnal variation of summer rainfall over subtropical East Asia. J. Climate, 25, 3307-3320, https://doi.org/ 10.1175/JCLI-D-11-00288.1.

Zhang, C. L., F. Chen, S. G. Miao, Q. C. Li, X. A. Xia, and C. Y. Xuan, 2009: Impacts of urban expansion and future green planting on summer precipitation in the Beijing metropolitan area. J. Geophys. Res., 114, D02116, https://doi.org/10.1029/ 2008JD010328.

Zhang, X., F. W. Zwiers, G. Li, H. Wan, and A. J. Cannon, 2017: Complexity in estimating past and future extreme short-duration rainfall. Nat. Geosci., 10, 255-259, https://doi.org/10.1038/ngeo2911.

Zheng, Y., M. Xue, B. Li, J. Chen, and Z. Tao, 2016: Spatial characteristics of extreme rainfall over China with hourly through 24-hour accumulation periods based on national-level hourly rain gauge data. Adv. Atmos. Sci., 33, 1218-1232, https://doi.org/10.1007/s00376-016-6128-5. 